\title{
Operational Experience and Evaluation of a Dual-Element Stretched-Membrane Heliostat
}

John W. Strachan and Jake Van Der Geest

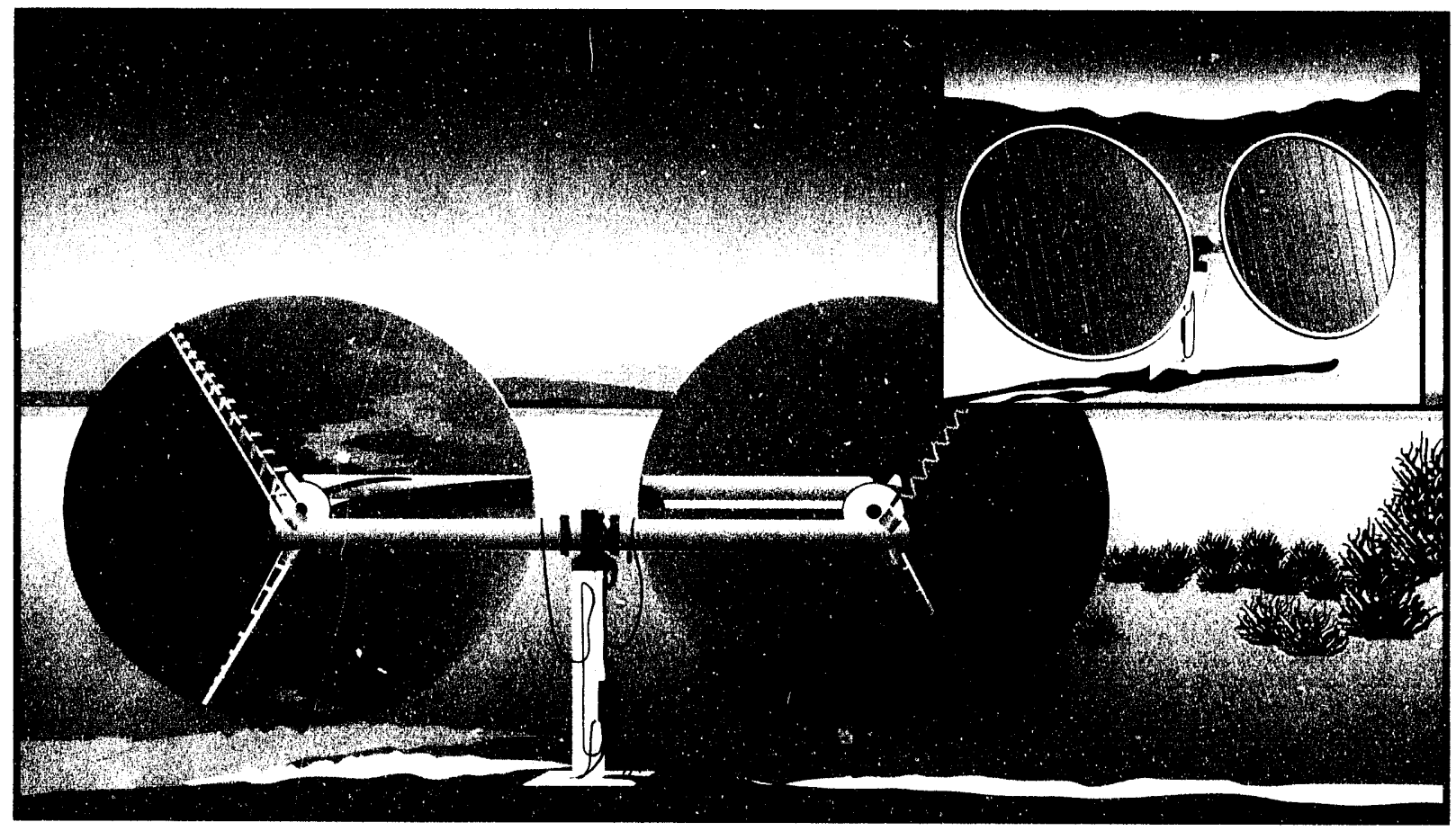


Issued by Sandia National Laboratories, operated for the United States Department of Energy by Sandia Corporation.

NOTICE: This report was prepared as an account of work sponsored by an agency of the United States Government. Neither the United States Government nor any agency thereof, nor any of their employees, nor any of their contractors, subcontractors, or their employees, makes any warranty, express or implied, or assumes any legal liability or responsibility for the accuracy, completeness, or usefulness of any information, apparatus, product, or process disclosed, or represents that its use would not infringe privately owned rights. Reference herein to any specific commercial produc, prosess, or service by trade name, trademark, manufacturer, or otherwisf, does not necessarily constitute or imply its endorsement, recommendation, or favoring by the United States Government, any agency thereof or any of their contractors or subcontractors. The views and opinions expressed herein do not necessarily state or reflect those of the United States Government, any agency thereof or any of their contractors.

Printed in the United States of America. This report has been reproduced directly from the best available copy.

Available to DOE and DOE contractors from

Office of Scientific and Technical Information

PO Box 62

Oak Ridge, TN 37831

Prices available from (615) 576-8401, FTS 626-8401

Available to the public from

National Technical Information Service

US Department of Commerce

5285 Port Royal Rd

Springfield, VA 22161

NTIS price codes

Printed copy: A03

Microfiche copy: A01 


\title{
Operational Experience and Evaluation of a Dual-Element Stretched-Membrane Heliostat ${ }^{1}$
}

\author{
John W. Strachan \\ Jake Van Der Geest \\ Solar Thermal Test Department \\ Sandia National Laboratories \\ Albuquerque, New Mexico 87185
}

\begin{abstract}
A dual-element, stretched-membrane central receiver heliostat was designed and manufactured in 1989 , by a private U.S. company engaged in the development of commercial central receiver solar technology. The two-module collector, with a collection area of $97.5 \mathrm{~m}^{2}$, extends stretched-membrane mirror technology on several fronts with face-down stow capability and a digital controller that integrates trackir, and focusing control on a single programmable control board. The solar collector was installed at Sandia's National Solar Thermal Test Facility in Albuquerque, New Mexico and evaluated over a three-and-a-half year period which ended in September 1993. The measured performance and the operational and Inaintenance characteristics of this commercial prototype are the subject of this report. The results of beam quality measurements, tracking repeatability tests, measurements of beam movement in elevated winds, performance tests of the focusing system, and all-day beam quality and tracking tests are presented, and we offer a detailed discussion of the knowledge gained through operation and maintenance and of the improvements made or suggested to the heliostat's design.
\end{abstract}

\footnotetext{
1This work was performed at Sandia National Laboratories, Albuquerque, New Mexico, and is supported by the U.S. Department of Energy under contract DE-AC04-94AL85000.
} 


\section{CONTENTS}

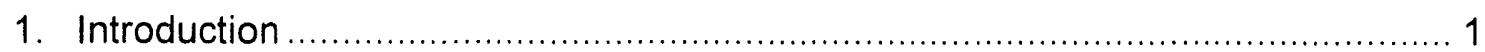

1.1. Recent Development History of Stretched-Membrane Collectors .......... 1

1.2. Description of the SAIC Dual-Element Heliostat ................................ 2

1.2.1. Tracking System ..................................................... 3

i.2.2. Optical System ........................................................ 4

1.2.3. Control and Electric Power Systems ................................ 5

2. Operational Experience and Performance Evaluation .....................................6 6

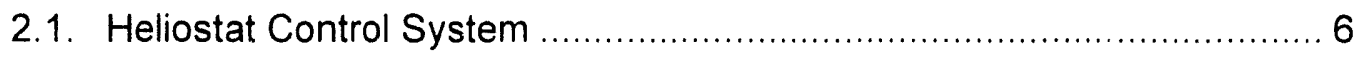

2.2. Optical System ..................................................................... 7

2.2.1. Operational Experience with Focus Controls ....................... 7

2.2.2. Beam Quality Evaluation ............................................. 7

2.3. Heliostat Drive System ...................................................... 14

2.3.1. Evaluation of Problems Affecting Tracking Performance ......... 14

2.3.2. Other Tracking Experience .......................................... 16

2.3.3. Heliostat Tracking Accuracy .......................................... 16

2.4. Heliostat Parasitic Power Consumption .......................................... 17

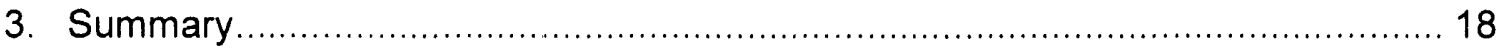

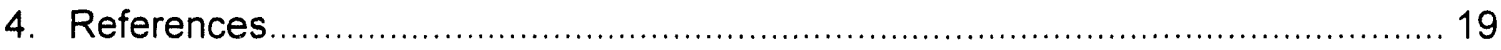

Appendix A: Plots of Wind-Induced Heliostat Beam Deflections ......................... A1

Appendix B: Summary of Problems Encountered While Operating the Heliostat ........ B1

Appendix C: Summary of Test and Operations Log ........................................ C1 


\section{FIGURES}

Figure 1: The SAIC Dual-Element Stretched-Membrane Heliostat............................ 2

Figure 2: Mirror Focusing Principle of the SAIC Modules ....................................... 5

Figure 3: Contour Plot of Optimal Heliostat Beam ........................................... 9

Figure 4: All-Day Optical Performance ........................................................ 10

Figure 5. Results of All-Day Beam Quality Tests............................................... 11

Figure 6: Canting-Related Mirror Pointing Error Over the Course of a Day ............... 12

Figure 7: Wind Event Group 1 ................................................................. 13

TABLES

Table 1: Recorded Wind-Effects Events .... 13 


\section{Introduction}

In 1989 , a prototype solar collector was designed by a U.S. solar technology firm, Science Applications International Corporation (SAIC), under contract to Sandia National Laboratories and then manufactured and installed by the firm at Sandia's National Solar Thermal Test Facility in Albuquerque, New Mexico. The heliostat is SAIC's thirdgeneration design of a stretched-membrane type collector.

This document reports the results of the testing and evaluation of that collector, which took place from late spring of 1991 until the summer of 1993. The report is organized around the two primary functions of stretched-membrane heliostats, tracking (keeping the collected solar beam on the receiver target) and focusing (maintaining the collector surface at the desired curvature).

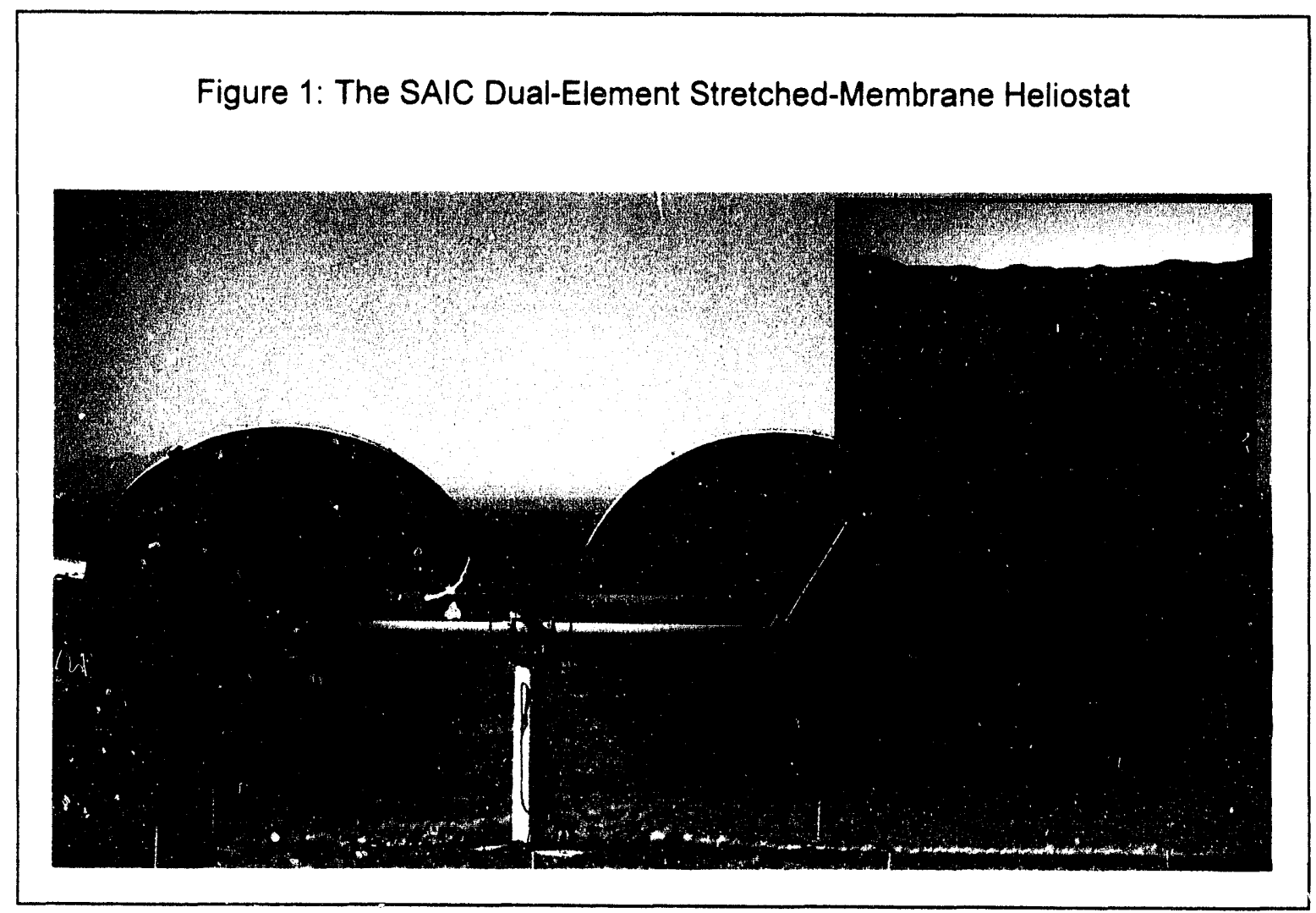

\subsection{Recent Development History of Stretched-Membrane Collectors}

Heliostat research and development is part of an ongoing national effort, sponsored by the United States Department of Energy, to develop central receiver technologies to harness solar energy for the generation of electricity. Because solar collectors, called heliostats, are the single most expensive subsystem of a central receiver plant, investments in research and development are aimed at improving performance and lowering cost.

The first heliostats produced in the program utilized glass mirrors [1 and 2], but in the mid1980 s heliostat designers in the program began to explore and develop mirror modules made of lightweight, flexible membranes upon which thin reflective films are applied. The first commercial use of membrane-type mirror modules in this country was by LaJet in a 
solar-powered electric plant in San Diego which employed point-focusing dishes composed of 1.5-meter diameter stretched-membrane facets. In 1986, the first full-sized $\left(50 \mathrm{~m}^{2}\right)$ stretched-membrane heliostat mirror modules were built under contract to Sandia by two U.S. solar technology companies, Science Applications International Corporation and Solar Kinetics Incorporated [3]. Second-generation prototype stretched-membrane heliostats were subsequently designed and manufactured by both firms between 1988 and 1989.

SAIC, as part of the design effort that led to its third-generation stretched-membrane heliostat that is the subject of this report, performed a manufacturing study [4], which produced estimates for the cost of manufacturing the dual-element heliostat and its lifetime operation and maintenance. Based on assumed production quantities of 5,000 units per year, the estimated installed cost in 1989 U.S. dollars is $\$ 107 / \mathrm{m}^{2}\left(\$ 10 / \mathrm{ft}^{2}\right)$ and the lifetime cost is $\$ 139 / \mathrm{m}^{2}\left(\$ 13 / \mathrm{ft}^{2}\right)$. This represents a reduction in cost of $20 \%$, compared with SAIC's estimate for the cost of the pedestal-mounted single-module stretched-membrane heliostats.

It is interesting to compare these cost estimates to those for glass-metal heliostats. A recent estimate for the installed cost of a glass-metal heliostat was provided by a manufacturing cost study performed in 1988 for a U.S. electric utility [5]. The installed cost was estimated at $\$ 135 / \mathrm{m}^{2}$ (also in 1989 U.S. dollars), ${ }^{2}$ based on an assumed production rate of 25,000 units at a steady rate over a ten-year period (half the rate used in SAIC's cost study). (Estimates of operations and maintenance costs were not provided.) One can conclude that dual-element stretched-membrane heliostats represent a very competitive option to glass-metal heliostats provided that the life of reflective films can be extended or an inexpensive way devised for their periodic replacement on installed stretched-membrane heliostats.

\subsection{Description of the SAIC Dual-Element Heliostat}

A principle goal of SAIC's design effort, which resulted in the dual-element stretchedmembrane heliostat, was to "determine if there are cost-effective alternatives to the pedestal heliostat design and to pursue the most promising of these alternatives." [4] One particular drawback of the pedestal-mounted single-module stretched-membrane heliostats is their inability to stow the mirror module in the face-down orientation; this results in increased degradation of the reflective material, increased soiling rates, and vulnerability to hail. The guiding objectives in the design of the SAIC dual-element stretched-membrane heliostat were to effect "cost savings in mass production and performance improvements over current pedestal-mounted designs by allowing face-down stow, by reducing drive component costs, and by optimizing the structure for the characteristics of stretched-membrane heliostats." [4]

Beninga et al. [4] provide a detailed description of the SAIC dual-element stretchedmembrane heliostat, and the following description draws freely from that document.

\footnotetext{
${ }^{2}$ The utility study's estimate was, in 1988 U.S. dollars, $\$ 131 / \mathrm{m}^{2}$, which I have converted to 1989 U.S. dollars based on the Producer Price Index for durable (non-food) consumer goods, Table B-61, page 867, "Economic Report to the President Transmitted to the Congress, February, 1992," U.S. Government Printing Office, 1992.
} 
The rear view of the heliostat depicted in Figure 1 provides a good vantage point for its description. Two 50- $\mathrm{m}^{2}$ mirror modules are mounted on a torque-tube drive assembly and each is supported along its circumference at three equidistant points: two trusses joined to the outer end of each of the elevation torque tubes extend to attachment brackets at the perimeter of each mirror module. A third bracket supports each mirror module and attaches directly to the torque tube. The torque tubes are attached to either side of the elevation drive, and the azimuth drive, which is located beneath the elevation drive, is mounted atop a steel-tube pedestal set in a concrete foundation.

The drives chosen for use in the dual-element heliostat are series planetary and wormtype drives manufactured by Peerless-Winsmith and powered by 1/4 HP 90VDC motors. Hall-effect encoders are incorporated into the drive motors to provide angular position feedback to the tracking control function. Limit switches positioned at the limits of safe travel in elevation and azimuth provide a mechanical disconnection of power to the associated drive motor. Another set of switches provide azimuth and elevation reference positions for the heliostat.

Each mirror module can be described as a shallow drum whose front and rear membranes are made of 0.005 -inch stainless steel foil. The steel (type 201) membranes are welded to an (A500) carbon steel ring to form a closed airtight plenum. A silvered polymer reflective film (ECP-305) is bonded to the front membrane to form the module's optical (energyreflecting) surface. To concentrate solar energy, this surface can, during on-sun operation, be drawn into a concave, light-focusing shape by exploitation of the principle of constant-volume described in detail further on.

Tracking and focusing functions are micro-processor controlled; these processors and their associated electronics are integrated onto a single control board, which is housed in a weather-tight enclosure affixed chest-high to the heliostat pedestal. The SAIC stretchedmembrane heliostat control board is one of the first prototype controllers to emerge from the DOE development program that integrates focus control and tracking functions in a single control board. This heliostat controller was developed under this program expressly for the dual-module heliostat.

The external interface for the heliostat control board is a personal computer (PC) connected to the heliostat control board over a serial-type interface. During our evaluation, the physical separation of the control board and the PC was approximately 700 feet.

\subsubsection{Tracking System}

The drives of the SAIC dual-element stretched-membrane heliostat are a PeerlessWinsmith Model 1151 elevation/azimuth drive unit. Both drives consist of a first stage planetary gear and a second stage (output) worm gear which results in a combined gear ratio of 18,400:1. These drives, which are of a self-locking design, were manufactured by Peerless-Winsmith for the DOE's second generation heliostat program; they were subsequently employed by ARCO in heliostats and photovoltaic trackers for three commercial applications, a solar-steam generator for enhanced oil-recovery in Taft, California, and two photovoltaic systems in California, one at Carrissa Plains and the other at the LUGO plant north of San Bernardino. The drives are powered by $90-V D C$ electric motors. They move the heliostat (in azimuth and elevation) at a rate in the range from 
$0.34^{\circ}$ to $0.37^{\circ}$ per second, and, during a 10 -hour day for the operation, they consume $580+/-50 \mathrm{WH}^{3}$

The Winsmith drives employed by the heliostat are early production units that were discovered to have excessive play or movement between the input and output gears. Details on this are provided in the Section 2 under "Play In Azimuth Drive Gear \& Resulting Drive-Motor Reversals."

The drive controllers are a part of heliostat control board. They employ Hall-effect type encoders to keep track of motor turns and heliostat position. Given the 18,400-to-1 gear ratio of the drives, it takes 51 revolutions of the drive motor to move the heliostat 1 degree. The result is that there are $0.02^{\circ}$ or $0.34 \mathrm{mr}$ per motor revolution. The Hall-effect encoders are mounted upon the output shafts of the drive motors and generate detectable pulses as the motor shaft rotates, 240 pulses per full revolution of the shaft. The pulses are counted by a dedicated pulse-counter chip incorporated into the heliostat controller.

\subsubsection{Optical System}

The modules' silvered reflective film maintained stable and high reflectivity during the evaluation period. The first measurement of module (solar-averaged specular) reflectivity was made in November 1990 (a year after the installation of the heliostat); the clean-mirror measured reflectance at that time was $0.94(+/-0.015)$. The last measurement, made in August 1993, yielded a clean-mirror value of $0.93(+/-0.015)$. Thus, the degradation of the film's solar-averaged specular reflectance was undetectable. The solar exposure of the reflective film during the evaluation period (three-and-a-half years) was considerably less than would be expected in a working heliostat field since we operated the heliostat perhaps a total of 150 days. Up until the end of the evaluation period (August 1993), there was no observable delamination in the film's layers, nor evidence of corrosion of the film.

One of the benefits of this heliostat's design is its ability to be stowed face-down, which reduces exposure of the reflective film to sunlight (particularly the degrading effects of ultraviolet sunlight), minimizes mirror soiling, and protects the reflective surface from damage by hailstones. By the end of the evaluation period, the numerous indentations from hail evident on the rear membrane of the mirror modules provided dramatic evidence of the value of the face-down stow.

\section{Heliostat Focusing Mechanism}

The system employed to focus the mirror modules has been patented by SAIC. The focusing process which is depicted in Figure 2 makes use of the fact that the plenum (volume of air) between the membranes is essentially sealed. A linear actuator, which is connected to a pad in the middle of the rear membrane, provides the focusing action. A linear voltage displacement transducer (LVDT), which is attached to the front membrane, measures that membrane's position, and that measure is employed by the controller as feedback in the focusing process.

When the linear actuator is retracted, a slight vacuum is created in the plenum between the membranes, pulling the front membrane into a concave shape and focusing the module. Likewise, extending the linear actuator pushes the rear membrane inward and causes the front membrane to assume a convex, defocused shape. During focusing

\footnotetext{
${ }^{3}$ This information is based on measurements made during the evaluation period.
} 
operations, the heliostat controller moves the linear actuator based on the position of the front membrane as reporied by the LVDT.

Since the module's plenum is not perfectly airtight, air leaks in gradually during the focusing operation and, in compensation for this, the linear actuator retracts the rear membrane. Eventually the actuator shaft reaches its limit of travel and the controller can no longer maintain the focus. To reduce the plenum back to a workable volume of air the controller opens the module's butterfly valve and moves the rear membrane inward to a defined position (called the neutral position). This inward movement of the rear membrane forces the expulsion of the excess air through the butterfly valve and temporarily defocuses the module. After a suitable time delay to expel the air, the controller closes the valve and resumes normal focusing operation. This control sequence for restoring the plenum's air volume is called a "burp cycle."

Note that during on-sun operation the heliostat would be defocused about $1 / 60$ th of the time since the "burp" cycle takes approximately 45 seconds and the interval between burps is about 45 minutes. In order to avoid defocusing the beams while expelling excess air from the plenum, SAIC has considered eliminating the focus system's butterfly valve and employing a fan

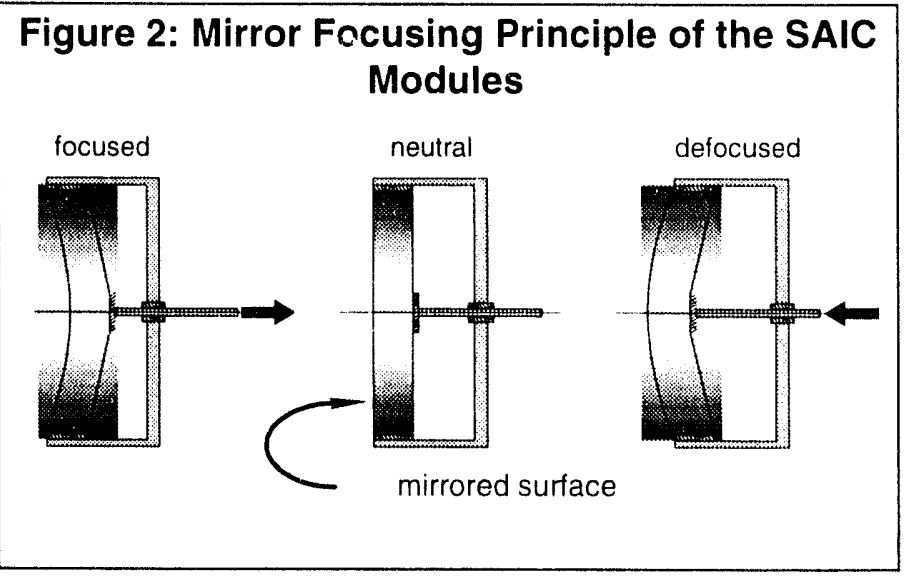
that would be turned on periodically to blow air from the plenum.

\subsubsection{Control and Electric Power Systems}

The heliostat controller and the power-processing subsystem are housed together in a weather-tight metal (type NEMA-12) enclosure mounted to the lower portion of the heliostat's cylindrical pedestal.

The controller is a microprocessor board that incorporates control and power functions for tracking and focusing. The control board includes a Motorola 68000 microprocessor with $64 \mathrm{~K}$ of dynamic RAM and $64 \mathrm{~K}$ of EEPROM (programmable memory). For commercial operation, the microprocessor is capable of being programmed to provide autonomous heliostat operation. That is, the controller need receive only high-level commands from the field control system; it can perform for itself ephemeris (sun-position) and tracking calculations and can generate the command sequences to drive the heliostat's tracking and focusing mechanisms. The control programming can be developed and compiled on a personal computer and then downloaded onto the controller's EEPROM via a serial port.

It was SAIC's original intent to download the C-language control program onto the controller, and to use a personal computer as the external interface with the controller. As a result of a problem experienced in the downloading process, the PC was made the platform for the control program which gives the controller its direction. SAIC eventually solved the problem, but time and resource constraints prevented them from rewriting the control program for direct use on the controller's processor. This is important, since some of the problems experienced with the control program, particularly its slowness of 
operation, were due to the slowness of the PC's processor and to the increased data transfer requirements placed on the communications line between the controller and the PC (a serial interface that employed RS-232 and RS-422 formats).

The control board is powered with 24-VDC power which the heliostat's power conditioning subsystem is equipped to rectify from $110-A C$ power. AC power is also rectified to provide 90-VDC power to drive the 90-VDC, 1/4-HP motors.

\section{Operational Experience and Performance Evaluation ${ }^{4}$}

\subsection{Heliostat Control System}

The evaluation period proved invaluable as a framework for identifying problems and making design and component changes to the conirol system, particularly the heliostat control board.

The control board was replaced several times over the evaluation period for a variety of reasons. Three control boards were manufactured, and during the evaluation they were used alternately while the current failed board was evaluated and repaired. The benefit to SAIC's design/development effort was substantial.

There were frequent over-design currents in the drive circuitry since the drive motors drew more current at the design load than originally specified, ${ }^{5}$ and we were frequently required to change the drive circuit's 10 -amp fuses. On one occasion, the fusing did not prevent the failure of one of the drive circuits on the board.

Toward the end of the evaluation period we experienced a failure of the serial interface between the PC and the controller. Because of the difficulty in fixing it, we simply replaced the RS-232 interface with an RS-422 interface.

Although the menu-type design of the heliostat control program was reasonable and was well and logically organized, using it to control the heliostat was somewhat cumbersome and awkward, primarily because of the length of time it took to move from one part of the program to another. The program ran too slowly; one would expect that heliostat control would prove to be inadequate for emergency operation. Movement within the menus to and from the most frequently needed heliostat commands or control actions proved to be very slow. The program's facility to permit the user to enter and change control parameters is not protected against accidental entry of erroneous values. For example, one can easily, by an accidental keystroke, make a blank entry into the linear-actuator neutral position parameter entry table and a value of 0 is entered, which will effectively cripple the module's focusing as the focus controller strives to retract the actuator past its lower limit.

In fairness, it should be noted that had the control program been implemented directly on the control board's own processor as originally planned, heliostat control operation would

\footnotetext{
${ }^{4} \mathrm{~A}$ "Summary of the Problems Encountered While Operating the Heliostat" is provided in an appendix to this report as is a "Summary of the Operations and Test Log." These are sources of additional details regarding the $O \& M$ experience gained with the SAIC dual-element stretchedmembrane heliostat.

${ }^{5}$ SAIC did not receive the motors from the manufacturer until after the control boards had already been built.
} 
probably have been much faster. As it was, the PC program was required to translate all user-commands into motor-drive or other machine instructions, and this seriously bogged down the execution time. In the commercial design this processing would take place onboard and the communication time between the PC and the controller would be considerably compressed.

In addition to that, the control program supplied by SAIC had many functions and capabilities which slowed its operation that would not be included in a commercial control program, but were supplied to facilitate the evaluation of the heliostat.

\subsection{Optical System}

\subsubsection{Operational Experience with Focus Controls}

Control of the mirror modules' focusing functions is mediated by the heliostat control program running on the personal computer. Adjustment of the focusing parameters is done from within that program.

The performance characteristics of the focusing system were established by means of a number of tests. The time required to focus and defocus the individual modules was found to be 8 to 11 seconds; the time required to open or to close a module's air valve was measured at 7 seconds. The time required for the module to expel excess air from its plenum (as the linear actuator pushes the rear membrane inward to the neutral position), is dependent on user-defined software parameters and ranges from 30 to 45 seconds.

When the various software parameters that govern focusing were set properly, the modules were able to maintain their focus for 25 to 55 minutes before a burp cycle became necessary.

The adjustment of focus parameters (from within the control program) proved to be difficult to master, and at times we were unsuccessful in obtaining a good focus. At times and for reasons that were not apparent, our focusing adjustments resulted in very short burp cycles. The fact that different units are employed within the control program to display LVDT and the linear actuator positions contributed to the difficulties.

On several occasions when the focusing parameters were improperly set, the control system got stuck in a loop in which the controller would repeatedly attempt to drive the rear membrane past its forward or rear limit of travel. We were never able to identify the precise cause of this problem. However, when properly adjusted, the focusing subsystem performed acceptably, producing a well-focused beam.

Some mechanical problems were encountered with the focusing subsystem during the evaluation period. The LVDT's mechanism was found to be vulnerable to moisture if not properly sealed after maintenance. On one occasion a linear actuator stuck in its fully retracted position and had to be replaced. On a separate occasion the over-temperature cut-off switch of the electronic actuator for the air valves on one of the modules was tripped and remained closed. The module was unable to focus, and it took a long time to discover the problem because we believed the heliostat control program was accurately displaying the status of the valves (open or closed) of the valve. In fact, the focus controller does not sense valve position but displays the condition to which it has commanded the valve. 


\subsubsection{Beam Quality Evaluation}

The term "beam quality" refers to the optical performance characteristics of a solar collector. The optical performance of the SAIC dual-element heliostat was evaluated using a beam characterization system (termed the BCS), which is a flux measurement system developed at Sandia's National Solar Thermal Test Facility [6]. A single BCS measurement is made by capturing and digitizing an image of the collector beam while it is being tracked on a large, fixed, flat target located on the vertical north-facing wall of the (test facility's) solar tower. The target is a white Lambertian (diffusely reflective) surface that reflects the beam uniformly. As a result, the distribution of light intensities in the image captured by the BCS camera is linearly proportional to the collector flux distribution itself. There is a flux gauge embedded in the target that provides a single absolute measure of flux intensity at one point in the beam. When analyzing the BCS image, this flux measure is employed to obtain an approximate flux conversion factor so that the pixel levels in the BCS image can be converted into flux intensity levels.

The BCS produces flux maps of a solar collector beam with a resolution as good as $1 \%$ and a measurement uncertainty of $5 \%$ or less for the relative flux distribution. The accuracy of the BCS's measures for the absolute flux level at any point in the beam is $6 \%$ at best and as good as $15 \%$ in most cases. This error estimate applies to flux levels at any particular point in the beam as well as to the total power in it. The measurement error varies depending on a range of variables [6], though the greatest error source is the measurement uncertainty of the flux gauges.

The system's image analysis capabilities make it a useful tool for examining and analyzing many aspects of solar collector performance, including dynamic effects over the course of a day or during windy conditions.

The BCS does not provide a measure of collector slope error, ${ }^{6}$ but the collector's optical performance can be modeled (using HELIOS) [7]. By comparing the actual flux map of the beam of a single stretched-membrane module with that predicted by the model, one obtains an estimate of the combined effect of average surface slope error and small-scale surface errors. That procedure was employed in the evaluation of the SAIC dual-element stretched-membrane heliostat and produced an estimated value of $0.8 \mathrm{mr}$ for these combined mirror slope errors for a single module. ${ }^{7}$ We made no uncertainty analysis of these results nor obtained a second independent measure or estimate that could be employed for comparison. Nonetheless, the estimate does provide an indication of that the collector surface slope errors are well below the DOE program's second generation heliostat specifications, which specify the theoretical beam shape plus a $1.4 \mathrm{mr}$ fringe or error [2].

\section{Sample Measurement of Beam Produced by Optimally-Canted Mirror Modules}

The focusing subsystem demonstrated the capability of producing well-focused, highquality beams. The heliostat's noontime performance on day 224 in 1992 is depicted

\footnotetext{
${ }^{6}$ The combined effect of average (root mean squared) surface slope error and small-scale slope errors (sometime referred to as "waviness").

7In HELIOS, for single heliostat modeling, the input parameter is the overall collector slope error and is intended to include mirror-module pointing error. Thus, for this analysis we modeled just a one of the modules and fixed the pointing error at zero.
} 
graphically in Figure 3 with a contour plot which maps the flux distribution of the collector beam. This image was taken several days after the mirror modules had been recanted so that we could obtain data on the heliostat performance in a condition of zero mirror canting error. ${ }^{8}$ With the two modules' beams fully overlapped, the peak flux in the beam was 13.8 $(+/-1.4) \mathrm{kW} / \mathrm{m}^{2}$, the beam's total power was $61(+/-6) \mathrm{kW}$. All flux in the beam having an intensity equal to or greater than $10 \%$ of the peak flux was contained within a circle (the black circle shown in the figure) having a diameter of $14 \mathrm{mr}$. (For comparison purposes, the nominal angular size of the sun itself is 9.3 $\mathrm{mr})$. Given the insolation level at the time of this measurement $(0.878$ $\left.\mathrm{kW} / \mathrm{m}^{2}\right)$, the normalized power produced by the heliostat was $69 \mathrm{~kW}$ which is $0.71 \mathrm{~kW}$ per square meter of collection area. This single BCS flux map exemplifies, perhaps, the best optical performance of the heliostat since the beams of the two modules are tightly overlapped. The balance of the beam quality evaluation was done with the modules

Figure 3: Contour Plot of Optimal Heliostat Beam

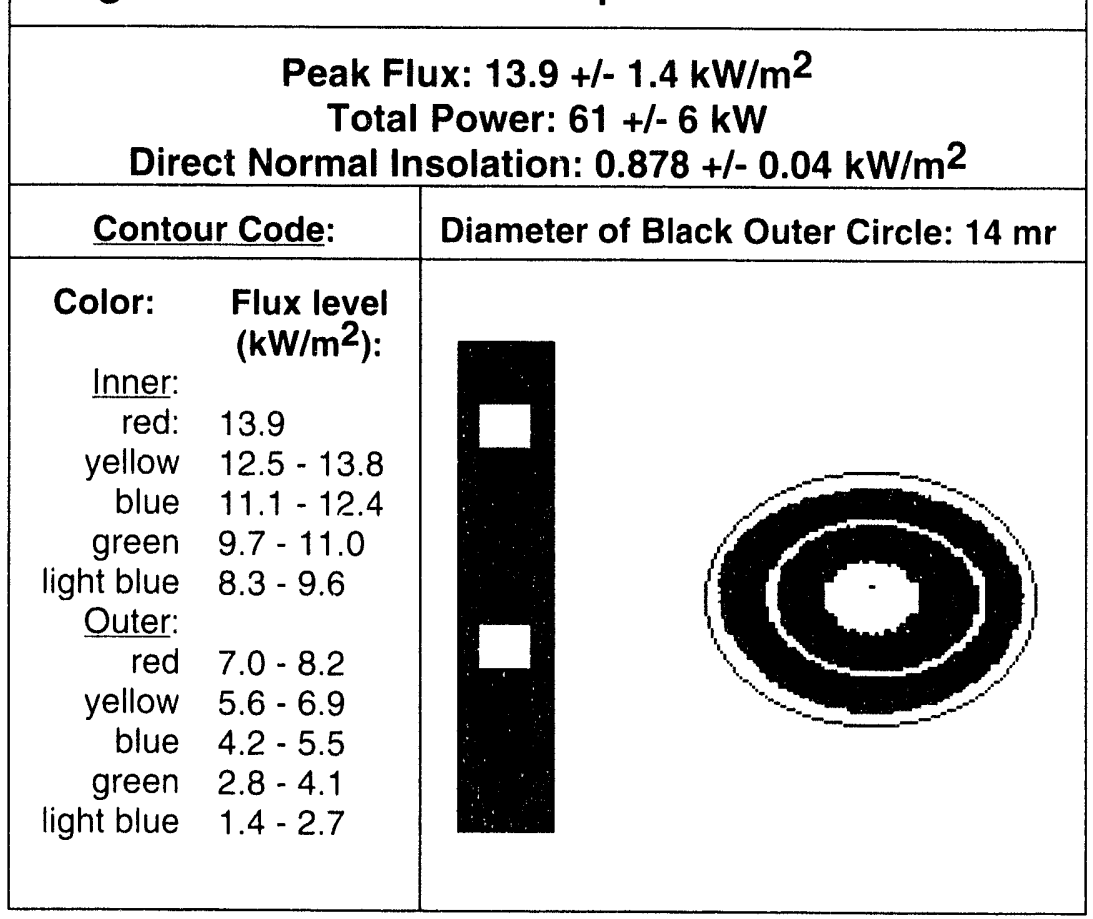
in their original canted condition, and the results of are presented below.

\section{All-Day Beam Quality Measurements}

In order to fully characterize the performance of the SAIC heliostat, an all-day beam quality test was performed using the BCS. This test involves taking and analyzing BCS images of the collector beam at frequent intervals over the course of a day. This test was performed over several days during the period of July $16-22,1992$. Figure 4 is a representative selection of contour plots of the BCS images of the heliostat beams. The contours in each individual plot are scaled to the highest flux level in that image. There are ten contours: the lowest (light blue) represents all flux that is $10-20 \%$ of the peak, the second contour (green) is $20-30 \%$ of the peak; and so forth. The 10:55 a.m. image includes a $10 \mathrm{mr}$ scale of the angular width of the beams (the same scale is applicable to all of the images).

8 This second canding of the heliostat was done at solar noon. 


\section{Figure 4: All-Day Optical Performance \\ (note scale in 4th image)}

The mirror modules were canted (aimed at a common point of the flux target) in midJanuary at about 2.5 hours before solar noon.

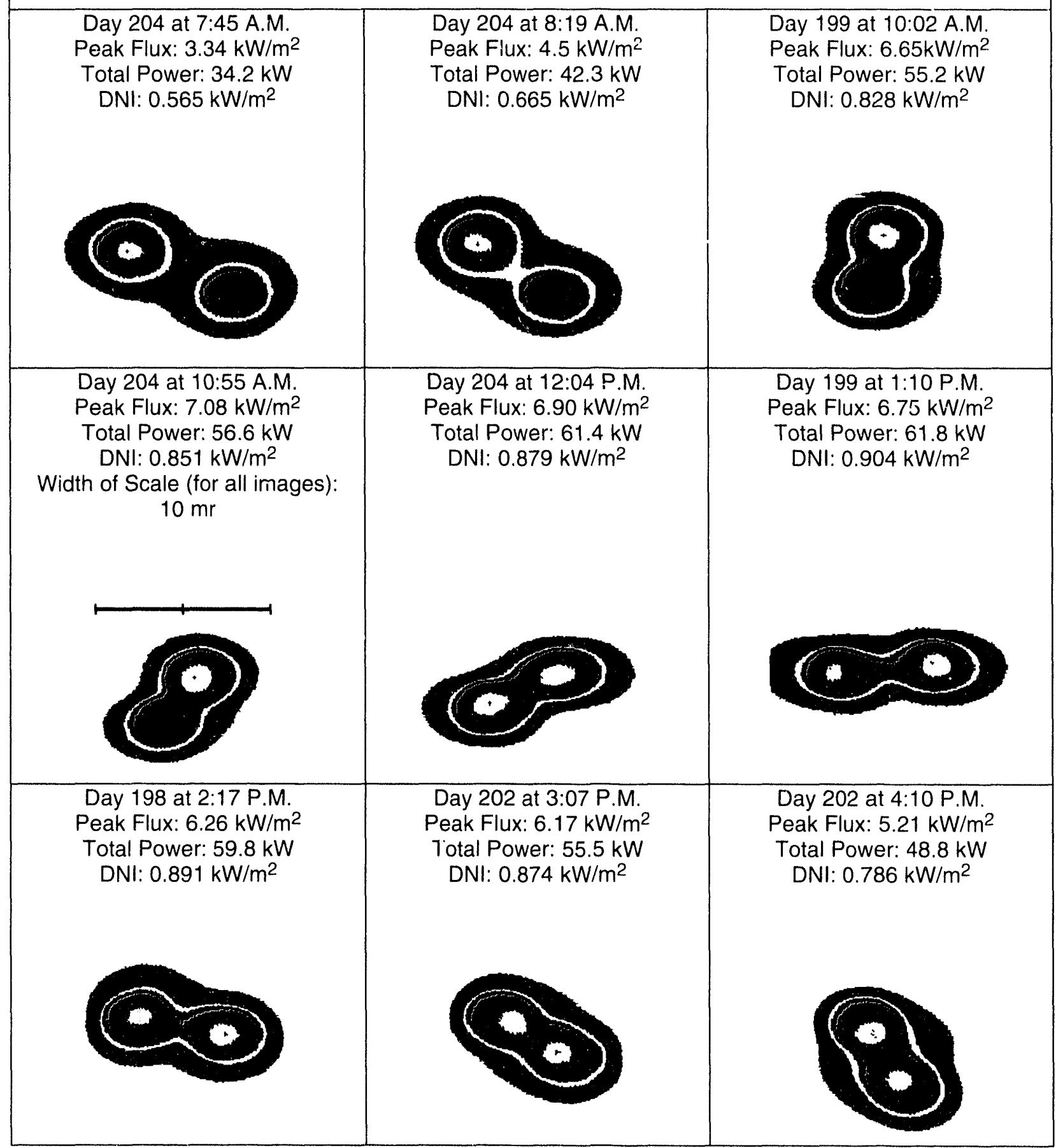


An analysis of the BCS data provided estimates of the total power, the peak flux, and the beam diameter for each BCS image obtained. These test results are plotted together in Figure 5. Color coding has been used to differentiate the four test days.

In the four hour-period centered around solar noon the average total power produced by the heliostat was $60+/ 6 \mathrm{~kW}$ with an average insolation level of $0.88+/-0.04 \mathrm{~kW} / \mathrm{m}^{2}$. When normalized to "one sun" $\left(1.0 \mathrm{~kW} / \mathrm{m}^{2}\right)$ this yields an average noontime performance of $68.2 \mathrm{~kW}$ of total power or $0.70 \mathrm{~kW}$ per square meter of heliostat collector area. The average peak flux during the same four-hour period was $6.5+/-0.6 \mathrm{~kW} / \mathrm{m}^{2}$. (We did not normalize this performance figure with respect to the heliostat's cosine losses, but in this evaluation the point on the elevation axis half-way between the heliostat's two mirror modules was located $50.3 \mathrm{~m}$ west, $249 \mathrm{~m}$ north, and $18.6 \mathrm{~m}$ below the beam tracking aimpoint.)

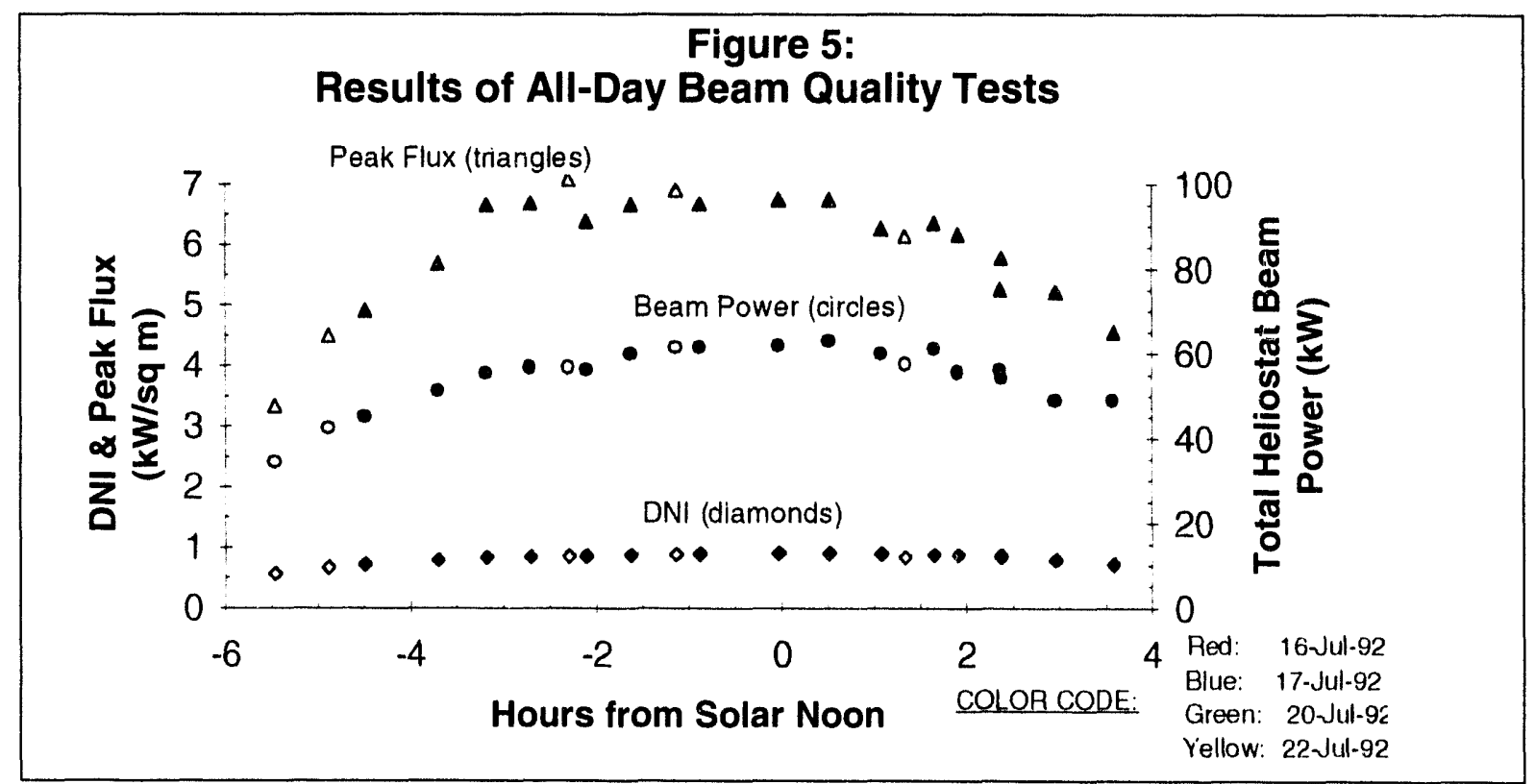

Mirror Pointing Errors and Module Canting Strategy

If a heliostat's mirror modules subtend a large angle, relative to the angular size of the solar receiver for which they are intended, then the canting or aiming of the modules is a design consideration with added significance. If the canting of the mirrors is performed only once (when the heliostat is first erected), then the modules' geometry is fixed. The receiver-to-heliostat-to-sun geometry, however, is not fixed, but varies with the sun azimuth and elevation angle over the course of the day and with the earth's declination angle over the course of the year. Consequently, the relative position of the module beams on the receiver will vary and the beams will generally not coincide. This constitutes a form of mirror pointing error. In the case of a heliostat with two circular, $8 \mathrm{~m}$ diameter modules, the year-long average angular separation of the beams will be considerable and is likely to be a much larger contributor to overall collector beam slope error than are the surface slope errors.

The mirror modules of the SAIC dual-element heliostat have manually-adjustable canting and were initially canted by the manufacturer at approximately two to three hours before 
solar noon in mid-January of 1991 . The consequences of this non-optimal canting were evident when the all-day beam quality test was performed in mid-July 1992. The module beams did not overlap one another (Figure 4) and the peak flux levels observed (Figure 5) corresponded to the flux produced by a single module.

To gauge the significance of the canting issue, an assessment was made of beam separation during the all-day tests and the results are plotted in Figure 6 . Over the course of a (composite) day, the beam separation was smallest several hours before and after solar noon. More significantly, the beam divergence increased in intervening four-hour interval by $4.6 \mathrm{mr}$. In other words, had the beam divergence been zero at $10 \mathrm{a} . \mathrm{m}$. and 2 p.m., then the maximum beam divergence would have occurred at noon and would have had a magnitude of $4.6 \mathrm{mr}$. This result does not quantify with any precision the year-long average beam divergence that can be expected in a two-module heliostat, but it does provide a single sample of the approximate scale of the problem,

Some small deflection of the SAIC module support structure at increased heliostat elevation angles is possible, and we performed no experiments to eliminate this as a possible contributor to module beam separation. Because of the structural efficiency of the module support trusses, we believe this effect would be minor or undetectable.

Attention will have to be given to the canting strategy for dualelement stretchedmembrane heliostats in order to minimize the pointing error due to a fixed canting. An analysis of this issie is recommended and could be performed using a heliostat modeling tool such as HELIOS. If that analysis should indicate the need, a mieans (manual or motor-driven) of

Figure 6: Canting-Related Mirror Pointing Error Over the Course of a Day

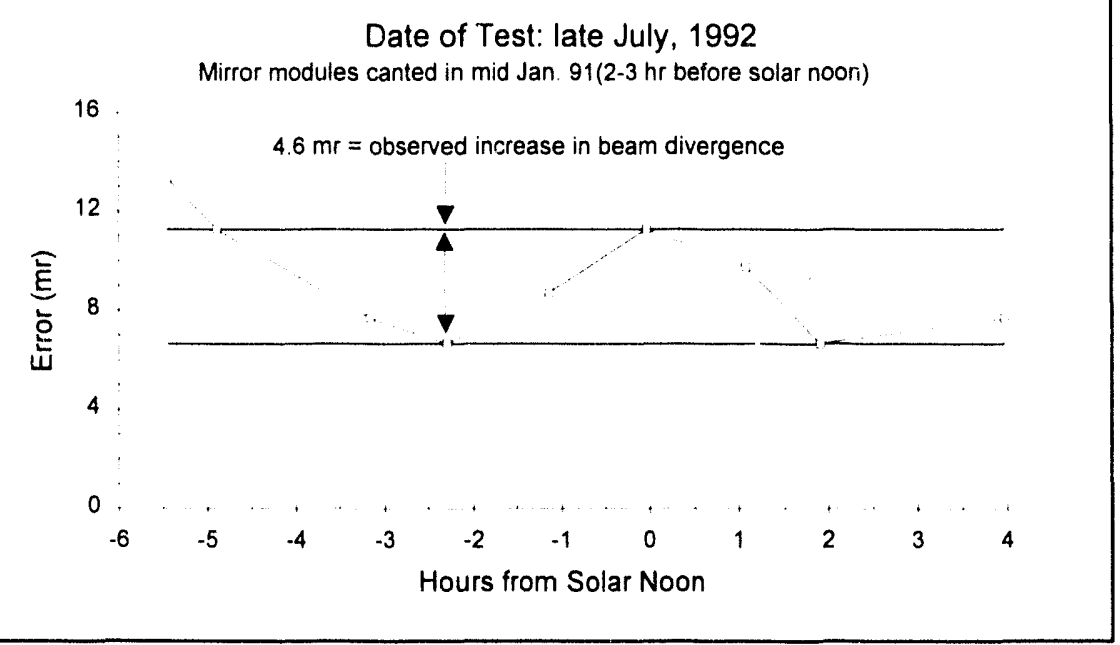

adjusting the module aim points could be incorporated into the heliostat's design.

\section{Optical Performance Under Windy Conditions}

Elevated winds can be expected to have two effects on the heliostat's optical performance, one due to the deflection of the solid members (the module support structure, the gear box and the heliostat foundations) and the other due to the deflection of the module (the support ring and the flexible reflective membrane itself). Deflection of the solid members appeared to be the dorininant cause of wind-induced beam movement and is what we measured. Our examination of the wind effects test data for evidence of module ring and surface deflection proved inconclusive. 


\section{Wind-Induced Beam Deflection}

During the evaluation of the SAIC dual-element stretched-membrane heliostat, wind effects tests were performed as wind conditions gave opportunity. As a result, twentythree wind events were recorded, each consisting of a sequential series of BCS images of the heliostat solar beam on the BCS target. ${ }^{9}$ The events recorded the motion of the heliostat beam on the receiver target during average wind speeds ranging from 13 to 31 $\mathrm{mph}$. Images of the beam on the target were acquired at a rate of 0.1 seconds per image in either full-resolution mode which yielded 48 images (a 4.8 second period) or in halfresolution mode which yielded 200 images (a 20 second period)..$^{10}$ The peak-to-mean ratio (the ratio of peak wind velocity to average wind velocity) in these observed events ranged as high as 1.36 but in only four events was the ratio greater than 1.3. The wind speed and wind direction (at a height of $10 \mathrm{~m}$ ) were measured concurrently with the capture of each image, and the heliostat's elevation and azimuth position were recorded to permit computation of the wind's angle of attack. The angle of attack in this context means the angle between the normal to the heliostat collection surface and the direction of the wind. To facilitate a qualitative review of the events, they were grouped by angle of attack (AOA), as per Table 1.

\begin{tabular}{|c|c|c|c|c|}
\hline \multicolumn{5}{|c|}{ Table 1: Recorded Wind-Effects Events } \\
\hline $\begin{array}{c}\text { Angle of Attack } \\
\text { (degrees) }\end{array}$ & $\begin{array}{c}\text { Wind Speed } \\
\text { Range } \\
\text { (mph) }\end{array}$ & $\begin{array}{c}\text { Number of } \\
\text { Recorded } \\
\text { Wind Events }\end{array}$ & $\begin{array}{c}\text { Largest Average } \\
\text { Beam Deflection } \\
\text { Observed (mr) }\end{array}$ & $\begin{array}{c}\text { Largest } \\
\text { Observed Beam } \\
\text { Deflection (mr) }\end{array}$ \\
\hline $29^{\circ}-34^{\circ}$ & $13-25$ & 4 & 2.0 & 7.6 \\
\hline $38^{\circ}-45^{\circ}$ & $16-25$ & 4 & 3.1 & 8.5 \\
\hline $80^{\circ}-91^{\circ}$ & $12-24$ & 4 & 2.1 & 4.7 \\
\hline $112^{\circ}-123^{\circ}$ & $15-28$ & 6 & 2.0 & 3.4 \\
\hline $126^{\circ}-144^{\circ}$ & $18-31$ & 5 & 2.5 & 5.5 \\
\hline
\end{tabular}

Figure 7 graphs the increase in heliostat beam deflection with wind velocity. The angle of attack of the wind for these four observations was between $29^{\circ}$ and $34^{\circ}$. The plots of the remaining four wind groups are provided for reference in an appendix to this report.

In all of the plots, the triangular data symbols represent the maximum beam deflection (in milliradians) observed during the wind event, while the square symbols represent the average deflection during the event. The straight lines are linear curve fits of the beam deflections. The decision to use a straight line fit rather than a second-order fit was arbitrary. No attempt was made to curve-fit the data in the $112^{\circ}$ to $123^{\circ}$ AOA range because, for that collection of observations, there was no observable relation between the beam deflections and the recorded wind speed.

\footnotetext{
${ }^{9}$ Performance of this test required not only elevated winds but also sunny conditions so that heliostat beam motion on the target could be recorded with the Beam Characterization System's camera.

10 The maximum capacity of the image digitizer board's memory for full and half-resolution images is 48 and 200 images, respectively.
} 


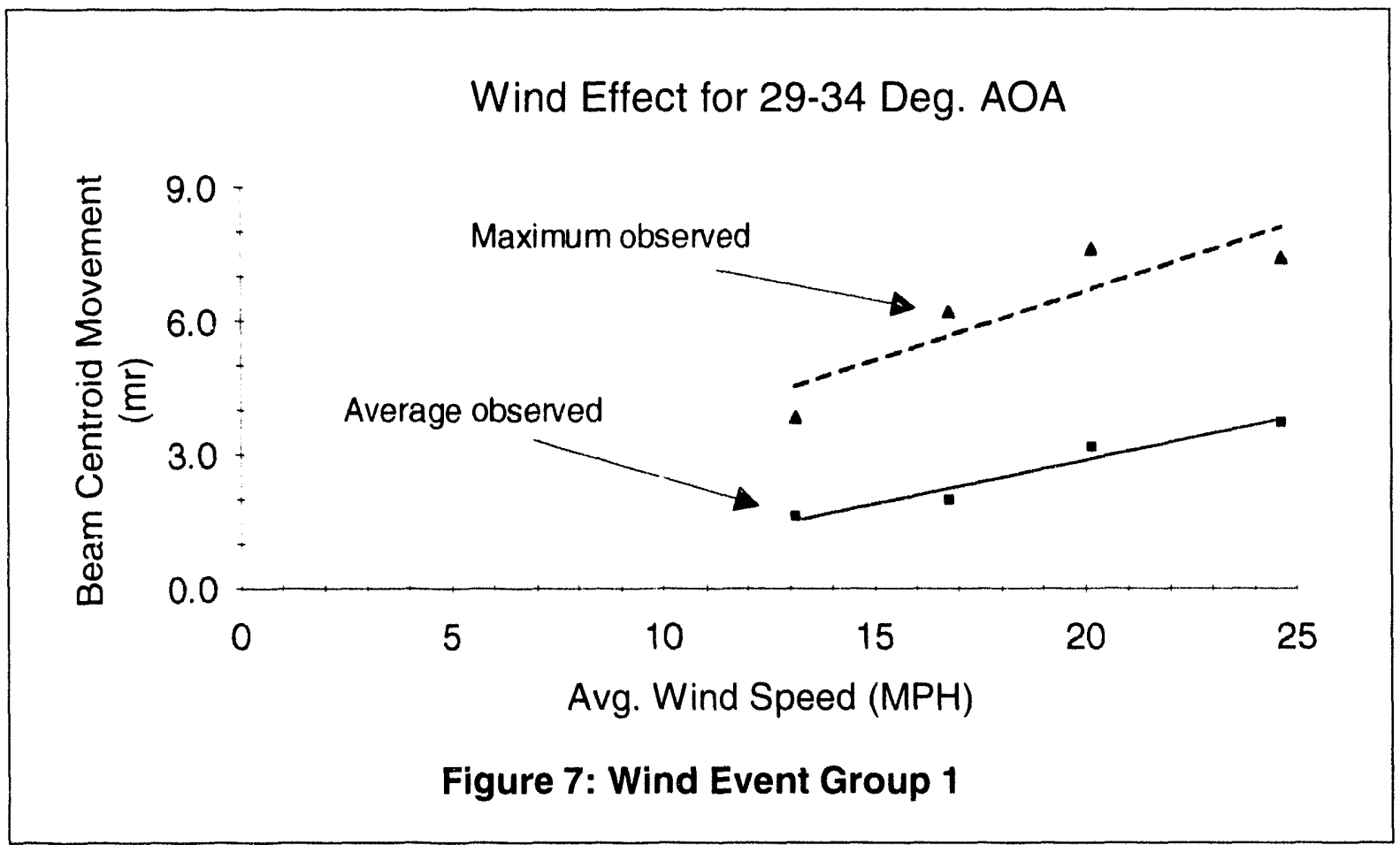

Measurements of the total effects of structural deflection under windy conditions suggests that the SAIC heliostat conforms to the second generation heliostat specification [2] which proscribes a maximum wind-induced deflection of the reflective surface of $3.6 \mathrm{mr}$ RMS in a $27 \mathrm{MPH}$ wind. Only once (in a 25- mph wind with an AOA of $33^{\circ}$ ) was the average beam deflection observed to exceed $3.6 \mathrm{mr}$, and during that event the average deflection was $3.73 \mathrm{mr}$. The average beam deflection observed in all the events recorded in the 25 to $31 \mathrm{mph}$ range (there were seven of them) was $1.9 \mathrm{mr}$.

\section{Effects of Elevated Winds on the Stretched-Membrane Collector Surface}

Unlike glass mirror modules, stretched-membranes can be deformed elastically. We evaluated the heliostat beam image data obtained during wind events and found evidence of only minor distortions of the membrane. But the conditions of the test did not permit us to easily quantify these findings nor permit us to draw conclusions. The existing wind effects data possibly retains some uncovered information regarding this effect.

\footnotetext{
11 Its worth noting, however, that these specifications, written before the advent of the strechedmembrane type heliostats, cannot be readily applied to them.
} 


\subsection{Heliostat Drive System}

\subsubsection{Evaluation of Problems Affecting Tracking Performance}

Three characteristics of the tracking subsystem were found to interact in a synergistic fashion to produce extremely large tracking errors ${ }^{12}$ over the course of only a few hours of on-sun tracking. The cause of the problem was determined to be the following: a) there was free play in the azimuth gear and a consequent tendency of the azimuth drive motor to coast; $b$ ) in response to the coasting, the drive motor tended to reverse directions frequently; and c) an artifact of the drive control board's encoder motor-counter chip caused it to lose counts whenever the drive motor's direction was reversed. A more detailed explanation of the problem is given below.

\section{Play In Azimuth Drive Gear \& Resulting Drive-Motor Reversals}

As a cost-savings measure, Sandia approved the use for the SAIC heliostat of an existing azimuth/elevation drive unit, Peerless-Winsmith's Model 1511. Unfortunately, a substantial play or free movemerit was observed in the unit's azimuth drive during the evaluation of the heliostat's tracking performance and this significantly impacted the heliostat's tracking accuracy. A simple set of tests indicated that for modest torsional inputs the heliostat could be made to rotate through an angular range of about $4 \mathrm{mr}$. This represents a significant source of random movement, and, during the evaluation of the heliostat's tracking accuracy, efforts were made eliminate the free play by pre-loading the drive with a pulley and weight system.

(Peerless-Winsmith manufactured only about 750 drives of this model, and the later versions of the model included an eccentric bearing ring, which made it possible to eliminate the source of this play by allowing adjustment of the center distance between the input and output gears.

As an ultimate solution to the backlash problem, Winsmith proposes replacing the model 1151 's azimuth (worm drive) with the (planetary gear) azimuth drive, which is in the Winsmith Low-Cost Drive.

As a result of the free play and the absence of a substantial pre-load in the dual-element heliostat's azimuth drive, the motor shaft tended to continue to rotate after it was turned off, and the desired azimuth position was frequently overshot. The controller would then command the motor to drive back in the opposite direction. The overall result was frequent motor reversals as the control system strove to reach the desired position.

\section{The Role of the Tracking Deadband}

The tracking deadband is a user-set parameter in units of motor counts that defines the permissible difference between the actual position of the drive motor and the position to which it is being commanded, and the units employed for the deadband parameter are motor revolutions or motor counts. When the heliostat is in a tracking mode, the controller continually computes the difference between the actual drive position and the desired position (based on computation of sun's position). When this difference exceeds the tracking deadband for a drive, then the control program runs that drive.

\footnotetext{
12The magnitude of accumulated tracking error varied but frequently exceeded $10 \mathrm{mr}$ or more after only a few hours of on-sun tracking
} 
It is important to note that the tracking deadband imposes a limit of resolution for tracking accuracy since the difference between the heliostat's actual and desired position can differ by as much as the tracking deadband.

By experimentation, it was discovered that the hunting behavior of the controller could be reduced (but not altogether eliminated) by increasing the azimuth tracking deadband to a value of 6 motor counts, suggesting that the azimuth motor generally coasted less than that amount. This solution, however, imposed a resolution limit on the controller of $2.1 \mathrm{mr}$ (0.35 mr per motor count).

\section{Encoder Pulse Counter}

During the investigation of the heliostat's poor on-sun tracking performance, a problem that was yielding large errors in the controller's count of drive motor revolutions was uncovered. The problem was in the programming (firmware) of the control-board's encoder pulse-counting chip, which has the task of detecting and counting the pulses from the Hall Effect encoder. The pulse counter program was designed to increment by one the value in a memory location each time a pulse was detected. During a full revolution of the drive motor shaft there were 240 such pulses generated. When a count of 240 was reached, the subroutine increments the motor revolutions counter by one and reset the pulse-count back to zero. Unfortunately, the program also reset the pulse-count memory to zero whenever the direction of rotation of the shaft was reversed, a procedure that resulted in the loss of some pulses. For example, if the pulse count were 209 when the motor came to a stop and reversed its direction, then the value of 209 in the pulse count memory location would be replaced with a zero, and that fraction of a revolution [209/240ths of one motor revolution which for this heliostat equals $0.35 \mathrm{mr}$ ] would not be passed on to the motor-revolutions counter.

Each reversal of the drive due to overshooting was accompanied by a corresponding loss in pulse counts. Since the heliostat was being driven westward all day, the total number of lost pulse counts would gradually build up, and the heliostat beam would gradually track off to the east of its intended target.

A similar interaction occured in the elevation drive when the heliostat was close to its horizontal (face-down) stow position. In this position there was very little load on the drive motors, which resulted in coasting and searching and the attendant accumulation of error in the elevation motor counts. Thus, frequent elevation drive motor reversals when the heliostat was sent to a stow position also caused loss of motor counts and elevation tracking errors.

Science Applications International Corporation has eliminated this flaw in the motorcounting function for future heliostat control systems. The function will be implemented by means of a single computer chip which will perform true quadrature encoder interpretation and thus be able to maintain an accurate pulse count when motor direction is changed.

\subsubsection{Other Tracking Experience}

\section{Motor-Mount Design}

The positioning of the azimuth drive motor-mount did not permit the use of a ratcheting wrench during the removal or installation of the drive motor. A minor change in the mount design would greatly reduce the motor installation time in a commercial version of this heliostat. 


\section{Motor Encoders Output}

Early in the evaluation, while troubleshooting heliostat tracking problems, it was discovered that the encoder voltage signal did not conform to the stated specification and as a result encoder pulses were not being detected and counted properly. SAIC modified the encoder circuit in the motors to fix the problem.

\section{Limit Switches}

The design of the limit switches at each end of travel for each heliostat drive axis was such that power to the affected drive was cut off completely if the heliostat exceeded the permissible range of travel. The consequence of this was the frequent and unnecessary task of manually actuating the affected drive to drive it off of the limit switch and restore automatic power to the controller. To avoid this problem in the future, SAIC redesigned the limit switch wiring so that power is cut off only in the direction of travel that is exceeded, thereby allowing the heliostat to be backed off the limit switch without resorting to manual operation.

\subsubsection{Heliostat Tracking Accuracy}

The problems described above were discovered during attempts to measure the all-day tracking accuracy of the heliostat. During such all-day tracking tests, the accumulated tracking error of the heliostat was observed to reach very large values such that the heliostat beam would eventually be tracked completely off of the solar tower. Although increasing the azimuth deadband (as described earlier) was found to significantly reduce the magnitude of tracking error, consistent and satisfactory tracking performance was never achieved.

Once the source of the tracking difficulty had been identified (as described above), two tests were employed to measure (within the constraints imposed by the above problems) the repeatability and the accuracy of the heliostat tracking system.

The tests evaluated the system's ability to move the heliostat away from a given (reference) position and then to return to that position. During the tests, a laser was mounted to the heliostat and aimed at a ground-mounted target; the heliostat was then placed in an arbitrarily selected reference position. The laser beam on the heliostat was aimed at the center of the target and then secured tightly (so that it would not move relative to the heliostat).

In the first of the tests, the heliostat was then commanded to drive away from the reference position by $30^{\circ}$ in elevation and $45^{\circ}$ in azimuth. Then the heliostat would be commanded to return to the reference position, after which the location of the laser beam would be noted (marked) on the fixed, ground-mounted target. The azimuth and elevation tracking deadband values employed during the test were 4 and 3 , respectively. These values imposed a combined limit of resolution of $1.75 \mathrm{mr}$ on the repeatability measurement itself. A few motor reversals were observed during this test; its results provide a conservative estimate of the heliostat's expected tracking accuracy in the absence of the problems described earlier.

The results of the first repeatability test suggested that acceptable tracking performance was likely if the problems described earlier (motor coasting, missed motor counts, etc.) 
were corrected. ${ }^{13}$ In the test, the tracking system's repeatability was found to be as good or better than the resolution imposed by the tracking deadband: in 10 trials of the test, the average difference between the original (reference) position and the return position was $1.5 \mathrm{mr}$. (The measurement uncertainty for the return positions was $0.25 \mathrm{mr}$.)

In the second test, the same procedure as above was performed, except that the heliostat was placed in the tracking mode for 30 minutes before being commanded to return to the reference position. In this test the position error upon return to the reference position was $3.2 \mathrm{mr}$, providing evidence that lost motor counts were indeed accumulating during just a short period of on-sun tracking.

\subsection{Heliostat Parasitic Power Consumption}

The tare input $(A C)$ power to the heliostat with the controller up and running and the heliostat in a ready, quiescent condition was measured at $35(+/-5) \mathrm{W}$. The power required to run the personal computer was not included in this measure.

Input power for heliostat drive operation was measured over portions of several days and these measures produced an estimate of $500-525 \mathrm{WH}$ for tracking operation over a 10hour day.

The focus subsystem's power consumption varied greatly depending on wind conditions. We estimate that a total of 25 to 100 Watt-hours would be required to provide focusing of the modules during ten hours of operation.

Based on these measurements, the total heliostat power consumption in a 10-hour day for focusing and tracking is 600 to $675 \mathrm{WH}$.

\section{Summary}

Except for all-day tracking, the heliostat proved capable of the basic operations and capabilities it was designed to perform. The controller subsystem demonstrated the concept and potential value of integrating tracking and focusing functions in a single control board. The hail damage evident to the rear membrane after only three and a half years demonstrated the great value of a face down stow capability.

It proved difficult to maintain the heliostat operational. SAIC responded quickly and efficiently to help identify the cause of each problem, and made numerous improvements in the design and the component selection.

Recommended design improvements, most of which were made by SAIC, include the following:

1. Implement the control program directly on the control board's programmable CPU to improve its functionality and make it "run" faster. (This was SAIC's original intent.)

2. Implement the limit switch circuit design so that drive power is cut off only in the direction of travel that is exceeded.

3. Modify the azimuth drive motor mounts to facilitate motor removal for maintenance and repair activities.

\footnotetext{
${ }^{13}$ The second generation heliostat specifications [1] that emerged from the DOE heliostat development program permit an RMS beam-pointing error of $1.5 \mathrm{mr}$.
} 
4. Use true quadrature encoder interpretation in the motor encoder pulse-counter to help insure that an accurate motor pulse count is kept.

5. Take extra measures to insure waterproofing of the LVDT housing after maintenance activities.

6. (SAIC is considering) the replacement of the module's butterfly valve with a blower, which, by cycling on and off, would maintain the proper air volume in the plenum while allowing the modules to remain focused. This would completely eliminate the loss of beam power from those modules in the heliostat field which at any given time are performing a burp cycle.

7. Explore the issue of optimal module canting. (It may be convenient to use an optical peformance modeling code such as HELIOS.)

8. Consider the possibility of providing a motor-driven means of adjusting the canting of one of the two mirror modules. 


\section{References}

1. C.L. Mavis, A Description and Assessment of Heliostat Technology, SAND878025, Sandia National Laboratories, Livermore, CA, April 1987.

2. J. W. Strachan and R.M. Houser, Testing and Evaluation of Large-Area Heliostats for Solar Thermal Applications, SAND92-1381, Sandia National Laboratories, Albuquerque, N.M., February, 1993.

3. D.J. Alpert, R.M. Houser, A.A. Heckes, and W.W. Erdman, An Assessment of Second-Generation Stretched-Membrane Mirror Modules, SAND90-0183, Sandia National Laboratories, 1990.

4. K. Beninga, R. Davenport, and J. Sundubrai, Selection and Design of a Stretched-Membrane Heliostat for Today's Markets, SAND89-7040, prepared for Sandia National Laboratories by Science Applications International Corporation, January, 1990.

5. P.G.\&E., RD\&D Solar Central Receiver Technology Advancement for Electric Utility Applications, Phase 1 Topical Report, Vol. 1, Report \#007.2-88.2, August 1988.

6. J.W. Strachan, "Revisiting the BCS, a Measurement System for Characterizing the Optics of Solar Collectors", SAND92-2789C, Proceedings of the 39th International Symposium of the Instrument Society of America, May, 1993.

7. F. Biggs and C.N. Vittitoe, The HELIOS Model for the Optical Behavior of Reflecting Solar Concentrators, SAND76-0347, Sandia National Laboratories, March 197?. 

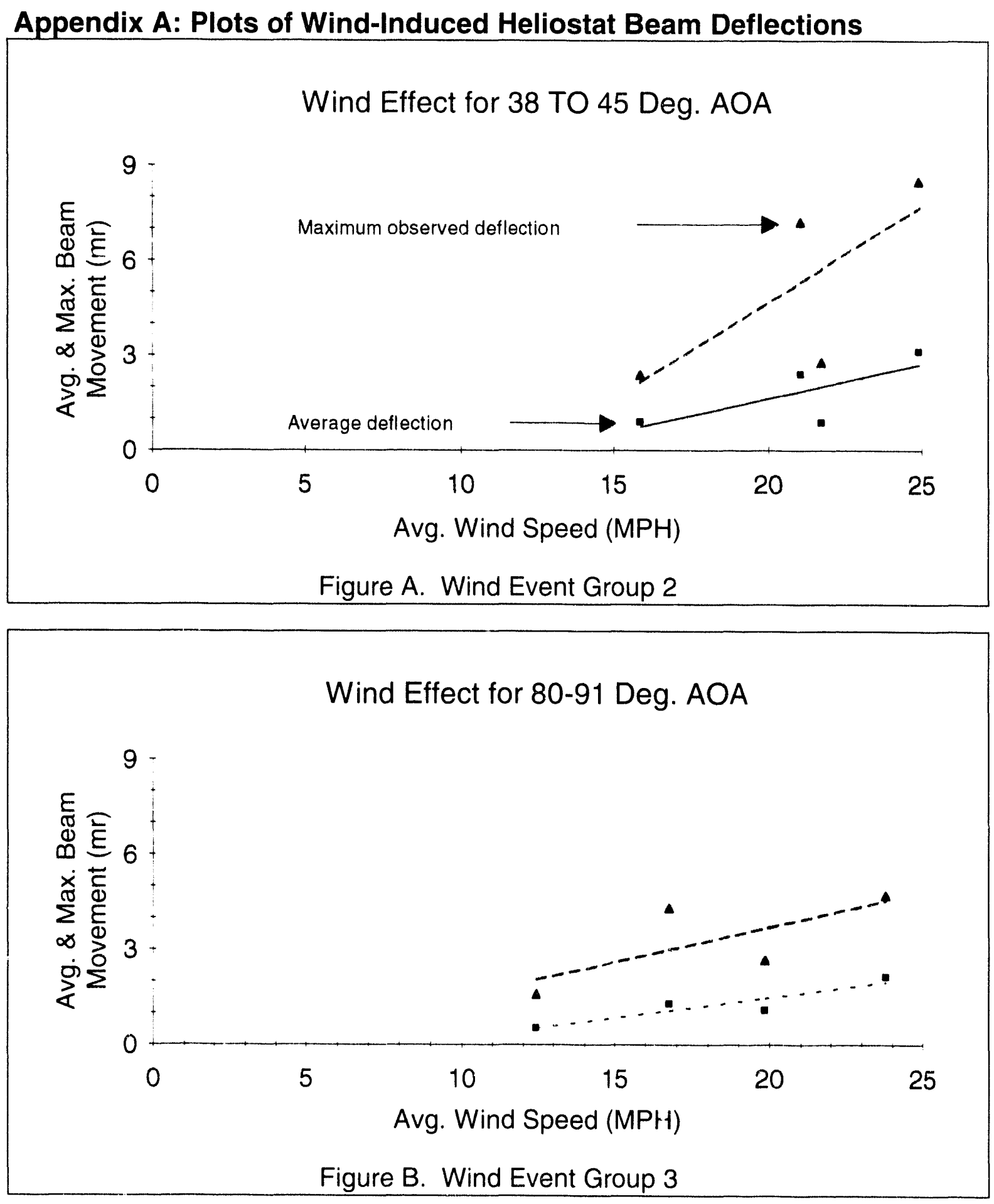


\section{Wind Effect for 112 TO 123 Deg. AOA}

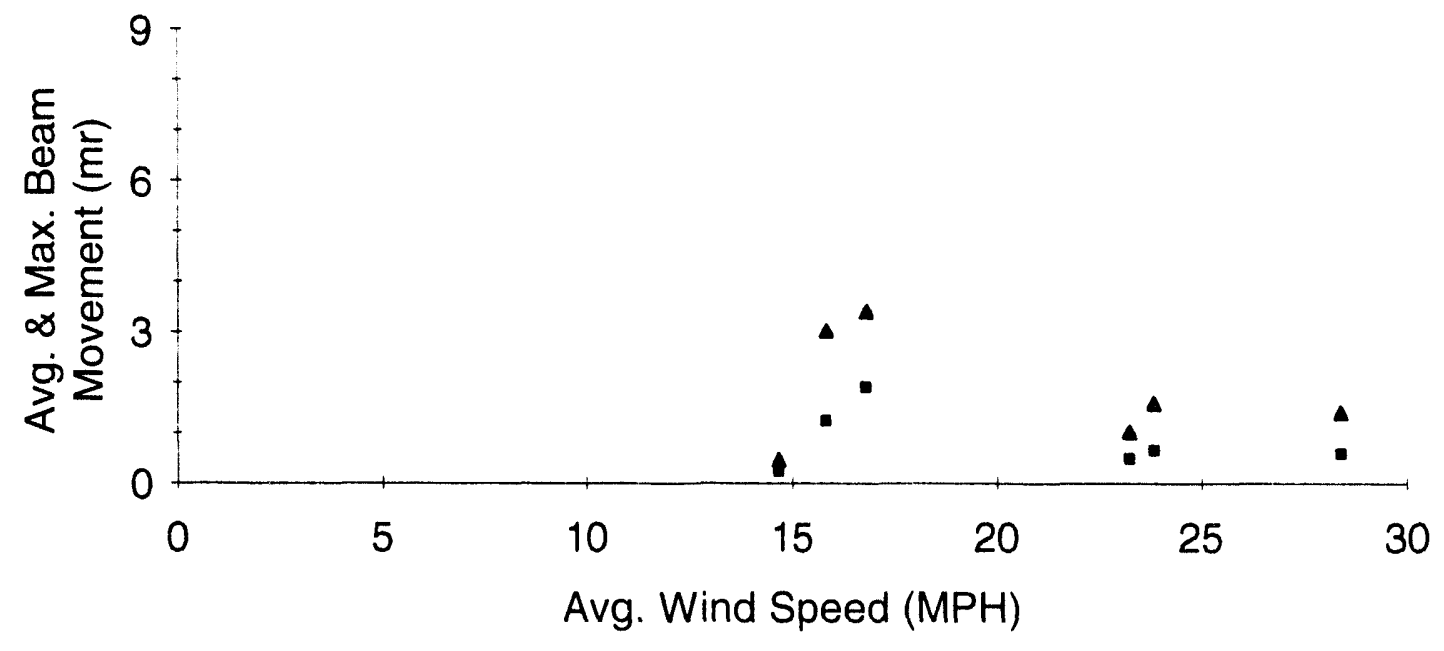

Figure C. Wind Event Group 4

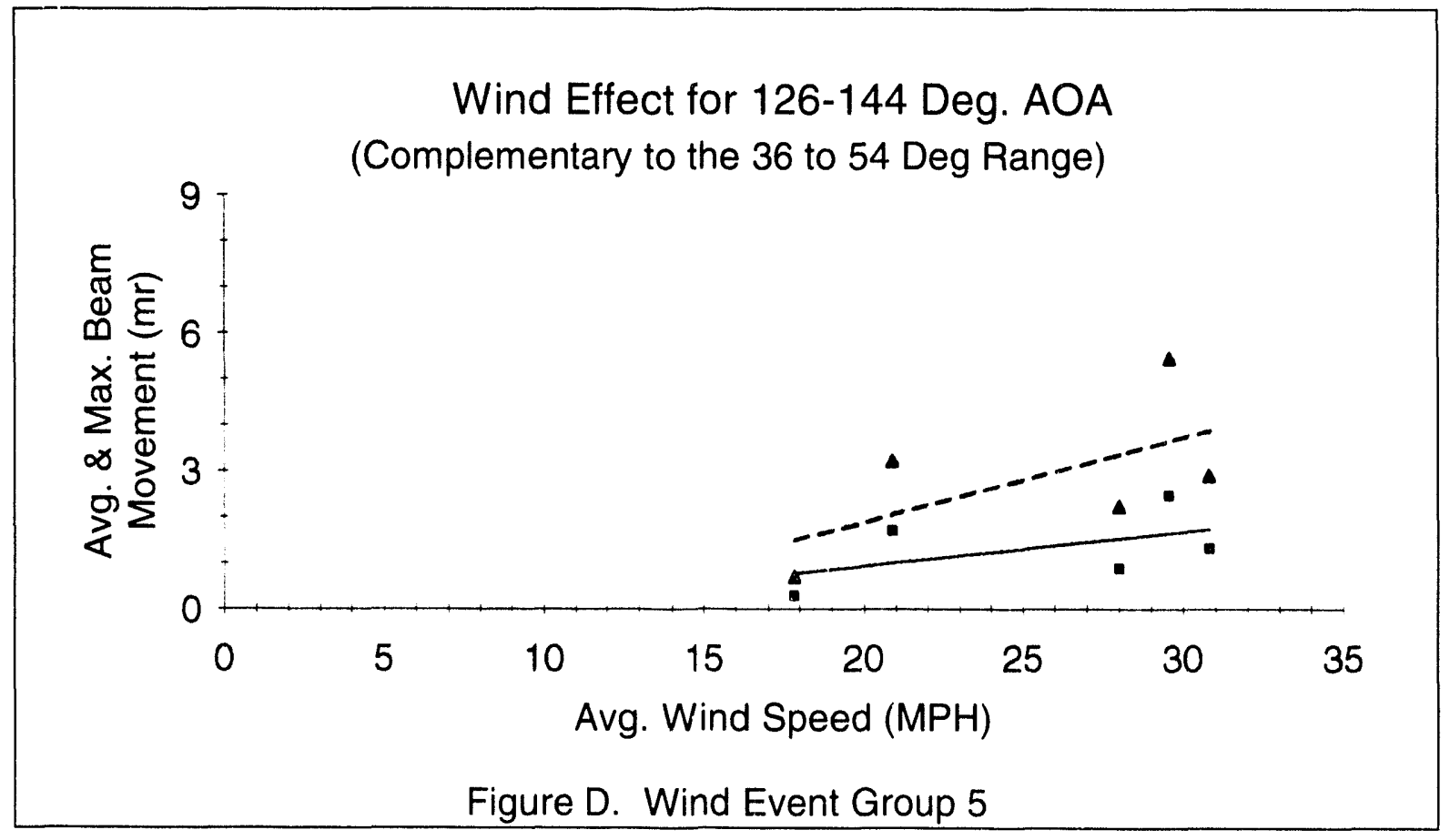




\section{Appendix B: Summary of Problems Encountered While Operating the Heliostat}

Note: The notes summarized in the following two appendices came from the Operations and Test Log which was kept over the course of the heliostat evaluation period. The persons frequently referred to are identified in this table.

\begin{tabular}{|l|l|}
\hline \multicolumn{1}{|c|}{ Name: } & \multicolumn{1}{c|}{ Role: } \\
\hline Roger Davenport & SAIC engineer \\
\hline Jake Van Der Geest & Sandia technician \\
\hline Dan Alpert & Sandia engineer \\
\hline John Strachan & Sandia engineer \\
\hline
\end{tabular}

The comments and notes below regarding operational difficulties were extracted from the Test and Operations Log

- 7/10/91: Heliostat was manually slewed down and east until both limit switches were tripped. The display, however, did not display the "REF" message for either drive to signals that its limit switch was tripped.

- New controller board installed 7/9/91 (at the SAIC-3 pedestal).

- At that time (7/91) there was a problem with the focus control for the right (west) module: the linear actuator (?) would strike the membrane repeatedly, making a loud thumping noise.

- 7/91: Fuses (2 amp, $250 \mathrm{~V}$ ) in the $E L$ and $A Z$ drive circuits were blown and had to be replaced. They were in the $\mathrm{F} 1$ location on the board.

- 7/91: Heliostat drives into the ED limit switch when sent to stow, despite adjustments made to stow position parameter.

- A discrepancy between actual and specified drive motor voltage characteristics resulted in erroneous motor counts by the encoder. Result was inability to track accurately. 1/15/92: From a memo to Dan Alpert, "Roger Davenport of SAIC notified me yesterday that he is shipping to us the drive motors for their dual-element, stretched-membrane heliostat. They had been troubleshooting them, attempting to determine why the heliostat controller was unable to track properly. They located what they think is the cause of the trouble in the Hall-effect encoders of the motors."

- 3/92: Trouble shooting failed controller board (elevation drive circuit)

* control board was replaced sometime around $3 / 8$.

- 3/92: Problems w/ focus control prevented BQ testing in mid March and early April.

Comment: Problems with the focus control included the difficulty of adjusting the various parameters. Add these to actual problems with the controls \& hardware itself.

- 4/3/92: "Problems w/ focus control prevented BEAM QUALITY testing..." (entry made 4/12)

- 4/12/92: Blown fuse for linear actuator circuit discovered and replaced. 
- 4/12/92: Only manual focusing of modules is possible; this problem disappeared after a new control board was installed on $4 / 17$.

- 4/17/92: "Newly repaired control board was installed. LVDT circuitry on the 'old' board was not working. New board works fine. Focus \& tracking functions seem operative..."

- 6/16/92: "Discovered blown azimuth drive circuit fuse \& replaced same."

- 6/92: Log notes indicate we were still observing the problem of "thumping" of the modules during attempts of the controls to focus.

- 6/26/92: Butterfly valves were stuck closed due to the tripping of a reset switch for the valves. Problem was solved when same was reset.

- 6/26/92: Above problem was not detected immediately, because there is no feedback to the control system on the valve's actual position (open or close).

- 6/26/92: Jake observed that the left linear actuator would "freeze" or stick and become immobile when commanded to the extreme extended position. That actuator was replaced on this date with one "found" on a shelf in our lab (Bldg. 9981).

- 7/1/92: Azimuth drive motor was replaced; the encoder was suspected of causing severe tracking error.

- 7/6/92: Elevation drive circuit fuse (8 amp) replaced.

- 7/9,10/92: Tracking difficulties prompted the replacement of the control board on the 9th. However, problems with the elevation drive circuitry on the "new" board led to it being replaced on the 10th with the "old" board. 


\section{Appendix C: Summary of Test and Operations Log}

- An acceptance test was performed in the spring of 1991. The heliostat proved capable of performing the most basic heliostat operations although it could not consistently track its beam accurately on a target.

- Although a substantial amount of operation and evaluation occurred before September, 1991, it wasn't until then that systematic test and evaluation began. The test and operations log was begun in that month (9/91).

- A new controller board was installed $7 / 9 / 91$ at the SAIC-3 pedestal. At that time there was a problem with the focus control for the right (west) module: a loud thumping noise was observed when attempting to focus the module; it appeared that the linear actuator was repeatedly striking the membrane.

The first BCS measurements were made at that time and stored in file G1921529.DAT \& *.WK1.

\section{7/12-17/91:}

- Fuses (2 amp, $250 \mathrm{~V}$ ) in the elevation (EL) and azimuth ( $A Z)$ drive circuits were blown and had to be replaced. They were in the F1 location on the board.

- Heliostat drives into the EL limit switch when sent to stow. We attempted to fix the problem by changing the EL stow parameter in motor counts. However, the result observed was that the $E L$ drive would drive into the limit switch, located at about $-80^{\circ}$ to $-85^{\circ}$, even though the display console indicated the position to be $-65^{\circ}$.

- Track trimming and quantitative tracking evaluation on 7/16 indicated the beams drifted away from their aim point by 3 to $5 \mathrm{~m}$ (slant range is about $300 \mathrm{~m}$, so drift is on the order of $10 \mathrm{mr}$ ) over a two or three hour period. (Remember, Strachan was doing a sequence involving using the TRIM command to get the beam to the aim point, then a counter reset command (TC) to zero out the motor counts. This is the procedure for zeroing out heliostat drive encoder error.)

- Pedestal tilt error measurements $7 / 16$ \& 7/17:

- TRIM and counter reset around solar noon on 7/16 and then again at around 9 a.m. on the 17th. After that, $A Z$ and EL position data pairs were taken. The actual AZ/EL position with the heliostat in auto track on the BCS target, and then the actual AZ/EL position after the heliostat had been manually moved (using TRIM command) to accurately position the beam onto the BCS aim point., i.e., the difference between these two AZ/EL measurements is the tracking error at that moment in time.

Davenport did a least-squares curve fit to pedestal tilt data which was measured directly with an inclinometer (and not the above tilt data).

- Date - mid-1991 Davenport came out to the NSTTF for several days to, among other things: (a) trouble shoot the focus control (he replaced a water-damaged spring in the linear actuator); and (b) replace the heliostat control computer (upgrade to a faster machine).

- 1/15/92: From a memo to Dan Alpert: "Roger Davenport of SAIC notified me yesterday that he is shipping to us the drive motors for their dual-element, stretchedmembrane heliostat. They had been troubleshooting them, attempting to determine 
why the heliostat controller was unable to track properly. They located what they think is the cause of the trouble in the Hall-effect encoders of the motors.

- 1/30/92: Sam Dunkin and John Strachan inspected the LVDT for the left module, and found it to be in good working condition. They verified the LVDT position (as reported from the control program) for various (manually adjusted) positions of the LVDT shaft. The log records a sequence used for tuning the focus control

- 2/26 \& 27/92: "Test days...lost...due to drive controls problem (see note of 3/2/92)."

- 3/2/92: "Trouble shooting failed controller board (elevation drive circuit)"

* control board was replaced sometime around 3/8.

* problems $\mathrm{w} /$ focus control prevented beam quality testing in mid-March and early April.

Comment: Problems with the focus control included the difficulty of adjusting the various parameters. Add these to actual problems with the controls \& hardware itself.

- 3/4/92 (date approximate) control board replaced.

- 3/13/92: "Problems w/ focus control prevented BEAM QUALITY testing..." (entry made 4/12)

- 3/17/92: Went through careful, detailed adjustment of the settings for the focus control.

- 4/3/92: "Problems w/ focus control prevented BEAM QUALITY testing..." (entry made 4/12)

- 4/12/92: Blown fuse for linear actuator circuit discovered and replaced.

- 4/12,17,22/92: Wind effects data obtained and stored in WIND EFFECTS 02 and the Bernoulli labeled "BCS \& Splitter" (then to be copied to WIND EFFECTS 03). The file names are G104hhhh.dat \& *.prn (hhhh=time) Note: no NIP data during these tests.

- 4/15,17,20,21,22/92: Beam Quality testing performed. Tables of times and sun positions given in log. Filenames are G106hhhh.DAT, etc. hhhh=military time of BEAM QUALITY measurement.

- 4/17/92: "Newly repaired control board was installed. LVDT circuitry on the 'old' board was not working. New board works fine. Focus \& tracking functions seem operative..."

- 4/21/92: During BEAM QUALITY testing, the tracking position required "trimming" several times by large amounts $(11 \&-3 \mathrm{mr}$ in the morning, and $4 \&-0.5 \mathrm{mr}$ in the midafternoon). It isn't clear from the log whether the TC (counter reset) command was used after the initial TRIM operation.

- 4/22/92: "At noon the right module developed an inability to fully focus. After an hour of experiment and investigation, the following conclusions:

1. Linear actuator unable to retract far enough to focus the module.

2. The (retract) limit is encountered at 400 (in linear actuator position feedback units).

3. Manual commanding of the linear actuator (LA) confirms that you cannot move the LA below the 424 position (even though the retract parameters "retract burp" and "retract limit" are 225 and 200, respectively. 
- Notes on Trouble-shooting of Right Module Focus:

1. Used command for manual movement of LA (FRMxxxx) to determine extreme retract and extend positions ( $350 \& 1210$, respectively).

2. Neutral position calculated as 860 , i.e. $\left(350+5 / 9^{*}(1210-350)\right.$.

3. Reset the focus position to that value, and then adjusted (gradually reduced) that value with the beam on the target.

- 4/22/92: Wind effects data taken with wind speeds in 14 to $25 \mathrm{mph}$ range. Data stored on Bernoulli's "Wind Effects 03" and "... 04".

- 6/10/92: New aim points established (by Jake) for BCS, BOTS, and UHCS. (see page 27 of $\log )$

- 6/12/92: "At tracking position 161.18 in AZ we lost ability to move in AZ; EL still OK".

- 6/16/92: "Discovered blown azimuth drive circuit fuse \& replaced same."

- 6/16/92 through 6/23/92 ( $\&$ beyond): Extensive trouble shooting \& "getting acquainted" with the focus control system.

- Hypothesis: It may be that the thumping observed so often in the focus control is caused by the control system improperly and repeatedly commanding the linear actuator to extend past the extend limit. It may be that the focus command "asks" for LA movement until the LVDT reading reaches the desired value which corresponds to "focused," regardless of the position of the LA During the execution of the focus command, the actual position of the LA is not observed by the program and as a result some mechanical limit is reached which produces the observed noise. Somehow, at this point, the result is a loop in which this happens repeatedly.

- 6/25/92: Butterfly valves discovered in fixed open position due to a "tripped" reset switch, which had to be reset manually before valves would open and close again. (May have been caused by excess heating brought on by excessive exercising of same.) This uncovered the fact that from the computer control console, the true status of the butterfly valve (closed versus open) is not displayed.

- 6/25/92: 55 mph winds; no wind effects data taken.

- 6/26/92: Left module linear actuator replaced. A problem encountered afterwards: the LA would stop when at approximate positions $460 \& 1060$ even though it hadn't reached the commanded position and there would be a 'whirring' sound. The LA would go no further but could be made to go in the opposite direction.

- 6/29/92: Extensive evaluation of the focus cycles. Also some important comments about difficulties when attempting to get accurate tracking of beams on the BCS target.

- 6/30/92: Repeated attempts to track the BCS target are documented. Problem is assumed to be backlash. However, Davenport suggests problem may be azimuth motor encoder.

- 7/1/92: Azimuth motor replaced. VanDerGeest notes: "(It is) very difficult to get to the motor mounts. They should be larger and further away from the housing so that you can get to the bolts with a ratchet."

- 7/2/92: Substantial drift in the azimuth beam position was observed (despite replacement of suspected $A Z$ drive motor encoder). 
- 7/6/92: Pedestal tilt data taken. EL drive fuse replaced.

- 7/9/92: Elevation drive fuse blown again. Heliostat control board replaced at 1 p.m. Several elevation drive fuses and one azimuth drive fuse were blown while driving the heliostat to various positions.

- 7/10/92: "The $0.5 \mathrm{ohm}$ resistor above the elevation drive's $8 \mathrm{amp}$ fuse was extremely hot yesterday in the p.m. ... was overloaded..." The old control board that was removed on 7/9 was replaced. The "new" board was shipped back to SAIC.

- 7/10/92: Pedestal tilt data taken.

- 7/13/92 through 7/20/92: Beam Quality data taken on days $14,16,17,20$, and 22 of July. Files are G196 through G204.

- 7/21/92: "Calculated slew rates"

- 7/22/92: Jake determined the locations of the limit switches.

- 8/4/92: Jake entered the pedestal tilt correction angles (alpha, beta, and gamma) into the heliostat control program.

$8 / 6,7 / 92$ Jake did counter resets and then commanded the heliostat to auto-track (TA). On both dates he noted that azimuth trimming was required to get the beam onto the BCS target. The amounts of AZ Trim were $-10,-5$, and $-23 \mathrm{mr}$. Unfortunately, Jake does not indicate in the log whether or not he reset the motor counter after this (by using the TC command).

- 8/7/92: Modules canted (see p. 47 of log).

- 8/11/92: Beam quality data taken. It shows the convergence of the module beams at noon, but a greater divergence away from noon than experienced prior to the recanting of the modules. Automatic tracking of the heliostat on the BCS target continues to incur very large errors, particularly in azimuth.

- 3/16/93: Jake prepared for Operational Testi in July 1992, and completed some of those tests. Results are in the "SAIC-3 Test Data" notebook. As part of same, he prepared a test procedure for measuring drive power consumption, but the test has not yet been performed. 
UNLIMITED RELEASE

INITIAL DISTRUBUTION

U.S.Department of Energy (3)

Forrestal Building

Code EE-132

1000 Independence Avenue, SW

Washington, DC 20585

Attn: Gary D. Burch

N. Haque

S. Gronich

U.S. Department of Energy (2)

Golden Field Office

1617 Cole Boulevard

Golden, CO 80401

Attn: Bob Martin

Project Manager

John W. Meeker

Contract Specialist

Advanced Thermal Systems

7600 East Arapahoe

Suite 319

Englewood, CO 80112

Attn: D. Gorman

Arizona Public Service Company

P. O. Box 53999, MS 1424

Phoenix, AZ 85072-3999

Attn: Scott McLellan

Joe McGirk

Asinel

Francisco Gervas, 3

Madrid 28020, SPAIN

Attn: Jesus M. Mateos

Atlantis Energy Ltd.

Thunstrasse 43a

3005 Bern, SWITZERLAND

Attn: Mario Posnansky

Babcock and Wilcox

91 Stirling Avenue

Barberton, $\mathrm{OH} 44203$

Attn: P. A. Bator

\author{
Battelle Pacific Northwest \\ Laboratory \\ P.O. Box 999 \\ Richland, WA 99352 \\ Attn: D. Brown \\ Kevin Drost \\ Bechtel National, Inc. (3) \\ 50 Beale Street \\ 50/15 D8 \\ P. O. Box 193965 \\ San Francisco, CA 94119-3965 \\ Attn: $F^{\prime}$. DeLaquil \\ B Kelly \\ R. Lessley \\ Black \& Veatch Consulting \\ Engineers \\ P.O. Box 8405 \\ Kansas City, MO 64114 \\ Attn: Larry Stoddard \\ Tom Brumleve \\ 1512 Northgate Road \\ Walnut Creek, CA 94598 \\ Bureau of Reclamation \\ Code D-3710 \\ P. O. Box 205007 \\ Denver, CO 80225 \\ Attn: Stanley Hightower \\ Ing. Rafael Cabarillas \\ Enrique B. Michel \#11 \\ Colonia Universidad \\ 83076 Hermosillo \\ Sonora, Mexico \\ California Energy Commission \\ 1516 Ninth Street, M-S 43 \\ Sacramento, CA 95814 \\ Attn: A. Jenkins
}


California Public Utilities Com.

Resource Branch, Room 5198

455 Golden Gate Avenue

San Francisco, CA 94102

Attn: T. Thompson

Central and South West Services

Mail Stop 7RES

1616 Woodall Rogers Freeway

Dallas, TX 75202

Attn: Edward L Gastineau

Centro Investigations Energetica (2)

Medroansental Technologie (CIEMAT)

Avda. Complutense, 22

28040 Madrid, SPAIN

Attn: M. Macias

M. Romero

Cermak, Peterka, \& Associates

1415 Blue Spruce Dr.

Fort Collins, CO. 80524

Attention: Jon Peterka

Darryl Boggs

Conphoebus

Sede Leg.

Via G. Leopardi, 60

95127 Catania, ITALY

Attn: Gino Beer

DFVLR, HA-ET

Linder Hoehe

P. O. Box 906058

5000 Cologne 90, GERMANY

Attn: $\quad$ M. Becker

M. Boehmer

Daggett Leasing Corporation

35100 Santa Fe Street

P. O. Box 373

Daggett, CA 92327

Attn: Wayne Lutton

EIR

$\mathrm{CH}-5303$ Wurenlingen, SWITZERLAND

Attn: W. Durish
Electric Power Research Institute

3412 Hillview Avenue

P.O. Box 10412

Palo Alto, CA 94303

Attn: E. DeMeo

D. Morris

Foster Wheeler Solar Development

Corporation

12 Peach Tree Hill Road

Livingston, NJ 07039

Attn: S. F. Wu

Hans W. Fricker

Breitestr. \#22

CH 8544 Rickenbach, SWITZERLAND

Georgia Power

7 Solar Circle

Shenandoah, GA 30265

Attn: Ed Ney

Dick Holl, President

Jenna Baskets

2475 Coral Street, Suite D

Vista, CA 92083

Idaho Power

P. O. Box 70

Boise, ID 83707

Attn: Jerry Young John Prescott

Interatom $\mathrm{GmbH}$

P. O. Box

D-5060 Bergisch-Gladbach, GERMANY

Attn: M. Kiera

KJC Operating Company

41100 Highwayt 395

Boron, CA 93516

Attn: Dave Ochenrider

S. Frier

Kearney \& Associates

14022 Condessa Drive

Del Mar, CA 92014

Attn: David W. Kearney 
Lawrence Berkeley Laboratory

MS 90-2024

One Cyclotron Road

Berkeley, CA 94720

Attn: Arlon Hunt

Los Angeles Department of Water

and Power

Alternate Energy Systems

Room 661A

111 North Hope Street

Los Angeles, CA 90012

Attn: Darryl Yonamine

Augi Garcia

Peter Lynch

Pacific Power

Park and Elizabeth Streets

GPO Box 5257, Sydney

New South Wales 2001 Australia

National Renewable Energy Lab (5)

1617 Cole Boulevard

Golden, CO 80401

Attn: Tom Williams

Mark Bohn

Nevada Power Co.

P. O. Box 230

Las Vegas, NV 89151

Attn: Mark Shank

Pacific Gas \& Electric

3400 Crow Canyon Road

San Ramon, CA 94583

Attn: Ray Dracker

Chris Haslund

Pasadena Water and Power Division 150 South Los Robles Avenue

Suite 200

Pasadena, CA 91101

Attn: Manny Robledo

Platforma Solar de Almeria (2)

Aptdo. 22

Tabernas (Almeria)

E-04200 SPAIN

Attn: M. Sanchez

W. Grasse
Public Service Co. of New Mexico

M/S 0160

Alvarado Square

Albuquerque, NM 87158

Attn: T. Ussery

A. Martinez

William Dayton Roberts, Sr.

2889 San Pascual St.

Pasadena, CA 91107

Rockwell International

Rocketdyne Division

6633 Canoga Avenue

Canoga Park, CA 91303

Attn: M. Marko, MS FA70

E. Baughmesiter

Sacramento Municipal Utilities District P. O. Box 15830

Sacramento, CA 95852-1830

Attn: Robert Wichert

Larry Wittrup

Salt River Project

Research and Development

P. O. Box 52025

Phoenix, AZ 85072-2025

Attn: Bob Hess

Ernie Palamino

San Diego Gas and Electric Company

P.O. Box 1831

San Diego, CA 92112

Attn: R. Figueroa

SCAQMD

21865 Copley Drive

Diamond Bar, CA 91765

Attn: Ranji George

Science Applications International

Corporation

2109 Airpark Road, SE

Albuquerque, NM 87106

Attn: D. Smith 
Science Applications International

Corporation (4)

15000 W. 6th Avenue, Suite 202

Golden, CO 80401

Attn: Davenport \& Beninga

Solar Kinetics, Inc.

P.O. Box 540636

Dallas, TX 75354-0636

Attn: J. A. Hutchison

Solar Power Engineering Company

P.O. Box 91

Morrison, CO 80465

Attn: H. C. Wroton

Southern California Edison

2244 Walnut Grove Avenue

P. O. Box 800

Rosemead, CA 91770

Attn: C. Lopez

I. Katter

M. Skowronski

Tom Tracey

6922 South Adams Way

Littleton, CO 80122

University of Houston

Solar Energy Laboratory

4800 Calhoun

Houston, TX 77704

Attn: L. Vant-Hull

University of Nevada at Las Vegas

Howard R. Hughes Coll of Engineering

4505 Maryland Parkway

Las Vegas, NV 89154-4026

Attn: Robert F. Boehm

Utah Power

1407 West North Temple

Salt Lake City, UT 84140-0001

Attn: lan Andrews

Jake Van Der Geest (2)

4201 Trinity Place, NW

Albuquerque, NM 87107 


\section{Internal Distribution:}

\begin{tabular}{|c|c|}
\hline 4521 & J. A. Leonard \\
\hline 4526 & Lori Parrott \\
\hline 5371 & S. Faas \\
\hline 5609 & A. Baker \\
\hline 6200 & D. E. Arvizu \\
\hline 6200 & D. J. Alpert \\
\hline 6201 & P. C. Klimas \\
\hline 6202 & G. J. Jones \\
\hline 6204 & N. J. Magnani \\
\hline 6211 & A. P. Sylwester \\
\hline 6212 & H. P. Stephens \\
\hline 6213 & T. C. Bickel \\
\hline 6214 & H. M. Dodd \\
\hline 6215 & C. P. Cameron \\
\hline 6215 & M. E. Ralph \\
\hline 6215 & E. E. Rush \\
\hline 6215 & J.W. Strachan (20) \\
\hline 6215 & Library (5) \\
\hline 6216 & C. E. Tyner \\
\hline 6216 & J. M. Chavez \\
\hline 6216 & G. J. Kolb \\
\hline 6216 & T. R. Maricini \\
\hline 6216 & D. F. Menicucci \\
\hline 6216 & J. E. Pacheco \\
\hline 6216 & M. R. Prairie \\
\hline 6216 & H. E. Reilly \\
\hline 6218 & D. E. Hasti \\
\hline 6219 & M. L. Whipple \\
\hline 7141 & Technical Library (5) \\
\hline 7151 & Technical Publications \\
\hline $7613-2$ & $\begin{array}{l}\text { Document Processing for } \\
\text { DOE/OSTI (10) }\end{array}$ \\
\hline
\end{tabular}

8523-2 Central Technical Files 

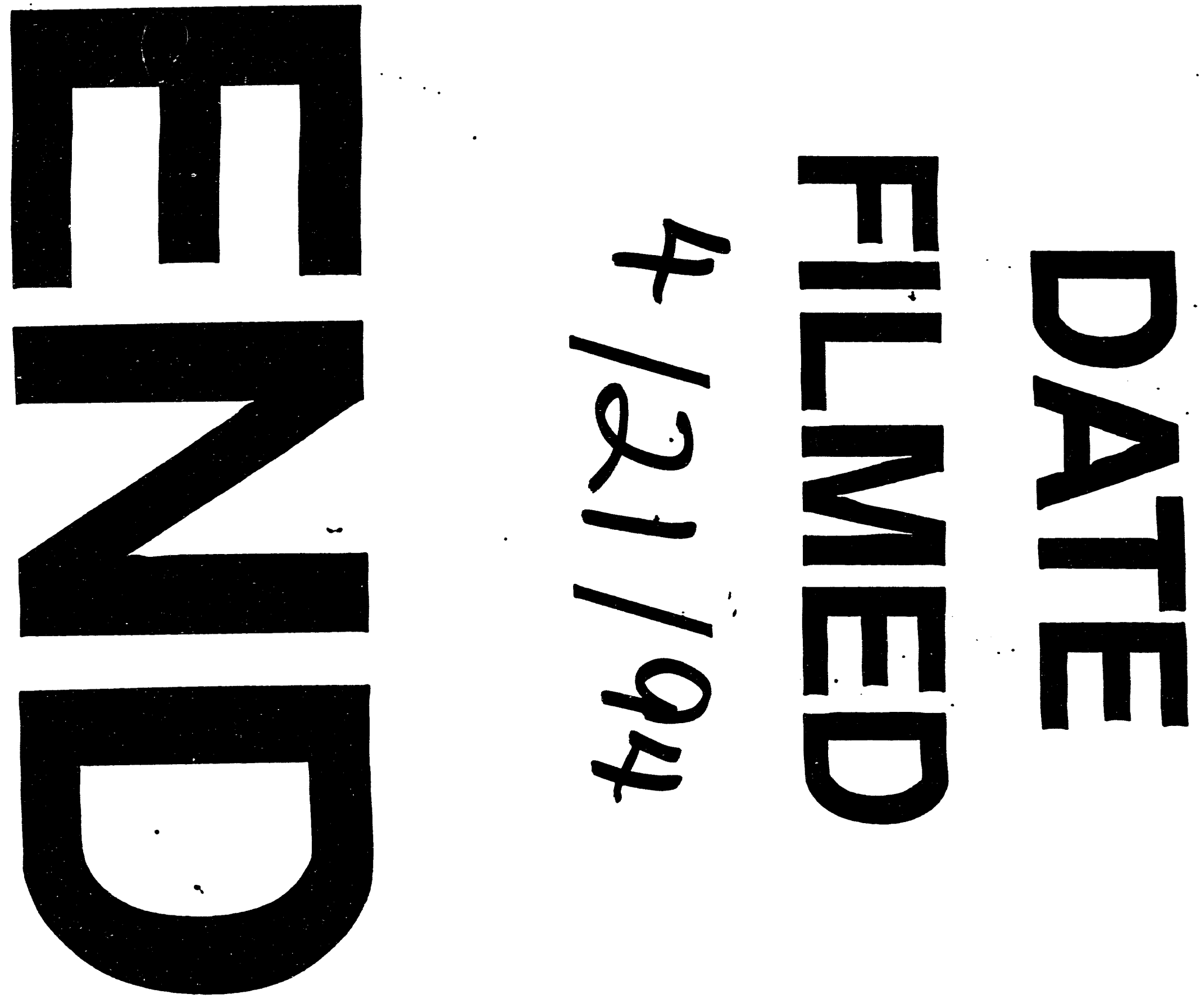